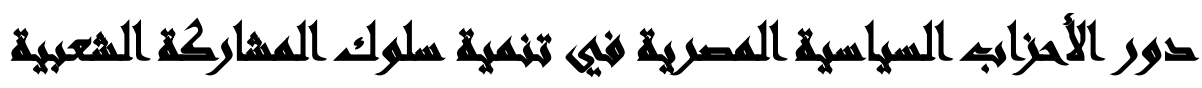

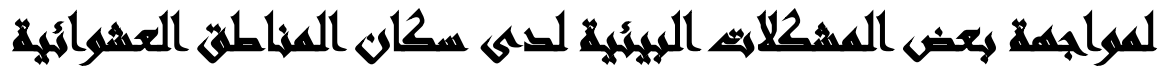

\section{[1r]}

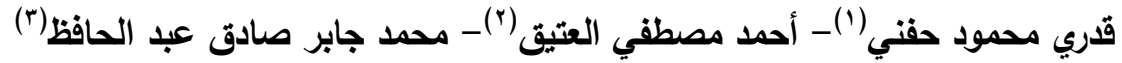

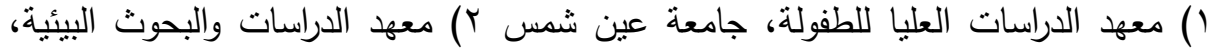
جامعة عين شمس r) المركز القومي للبحوث الإجتماعية والجنائية

\section{المستخلي}

تتاولت هذه الدراسة موضوع دور الأحزاب السياسية المصرية فى تتمية سلوك المشاركة الثعبية لمواجهة بعض المشكلات البيئية لدى سكان الإنية المناطق العشوائية ولندرة الدراسات

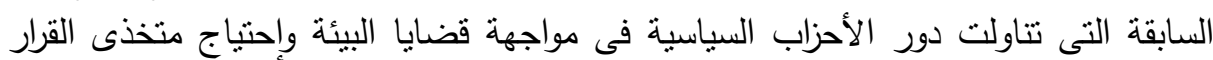
لمتل هذه الدراسة لذلك قامت هذه الدراسة بهدف التعرف على التى دور الأحزاب السياسية في كيفية تتمية سلوك المشاركة الثعبية لمواجهة المشكلات البيئية التى بعاني منها سكان التهان المناطقة

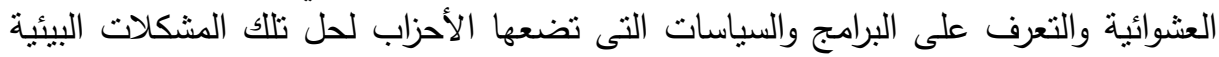

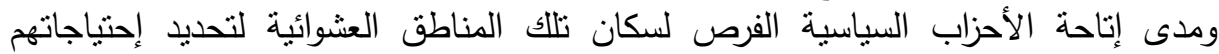

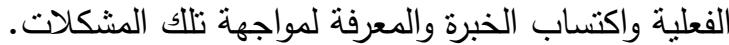

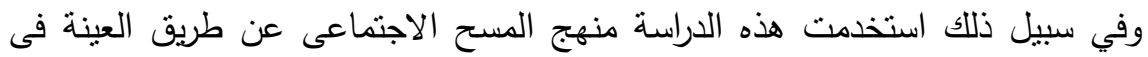

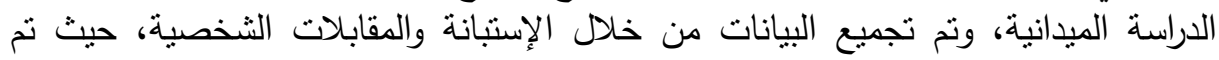

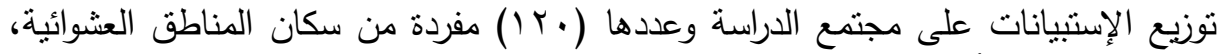
و و(^) مفردة من أعضاء الأحزاب السياسية.

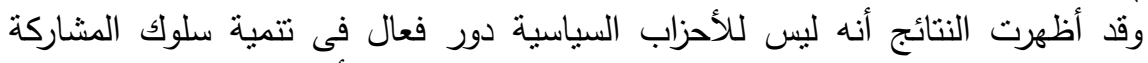

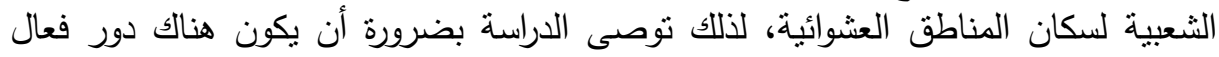

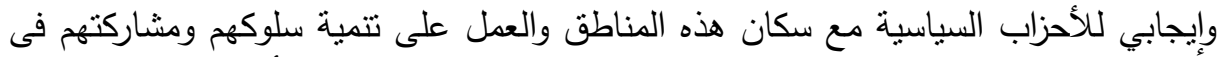

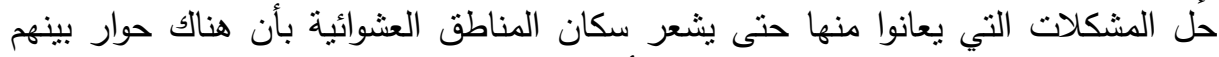

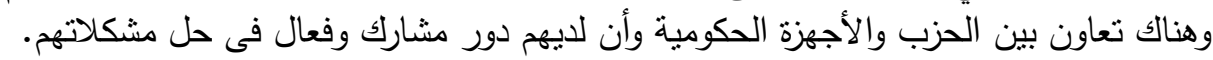


مجلة العلوم البيئية

معهد الدراسات والبحوث البيئية - جامعة عين شمس ليه

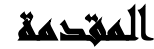

مما لاشك فيه إن حق الإنسان الذي تتبع منها جميع الحقوق الأخرى يتعرض اليوم

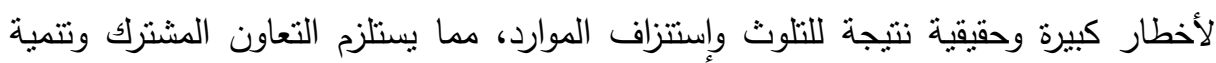
سلوك المشاركة الثعبية وتضافر جهود كل البشر لحماية البيئة، بل لحماية حق الإنسان ولذلك فإن الدفاع عن البيئة أوحمايتها يجب أن ينبع من المنظمات الجماهيرية التي تستطيع

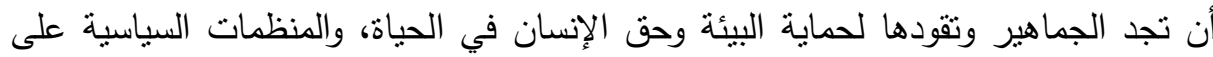
وجه الخصوص لها دور ملموس في إسنتارة الجماهير وقيادتها لمواجهة مشكلاتهم المجتمعية لهنية وتعبئة طاقتهم من خلال التتظيم السياسي القائم، بل أنها تتميز بقدرتها على القرارات السياسية وتوجيهها لما فيه خير للإنسان، والأحزاب السياسية عادة تضم عدد كبير من صفوة المجتمع. ومن خلال التجارب العربية والعالمية والدراسات التي أقيمت حول العشوائيات أظهرت

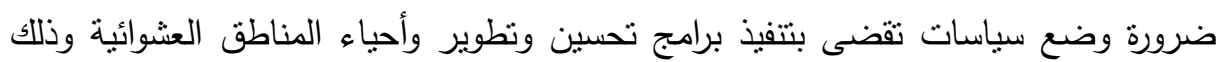

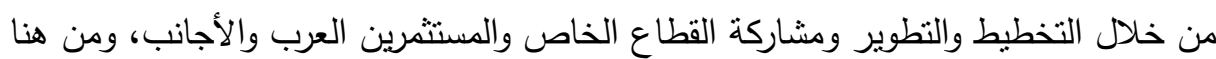

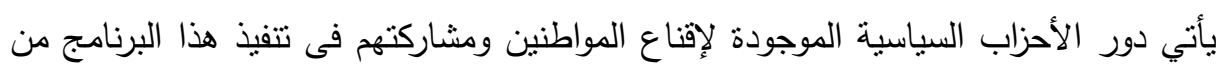
خلال نظافة شوارعهم، ونتجيرها، ودهان واجهاتها، وتوفير معلومات مباشرة عن الوحدات

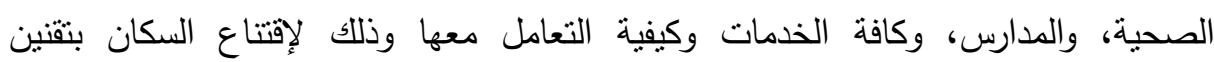
أوضاعهم وتمليكهم الأراضى التي تم البناء عليها عشوائيا وإقناعهم بالمخططات الجديدة. وتعانى العشوائيات في مصر من نقص أوعدم وجود المرافق الأساسية والخدمات ولذلك

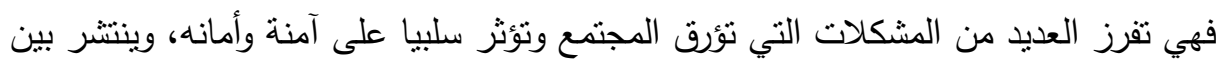

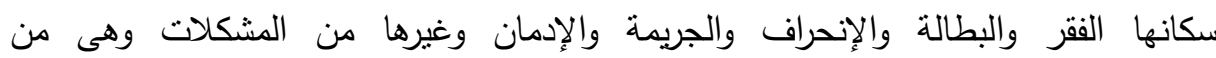
الخصائص العامة لهذه المناطق. والأحزاب السياسية الموجودة في مصر الآن بصل عددها تقريبا نحو هب حزبا سياسيا ولابد أن تقوم هذه الأحزاب بدور رئيسيا في تتمية سلوك المشاركة الشعبية من خلال نشر فرد الوعي البيئي بين المواطنين لحل مشكلات البيئة المختلفة التي تهدد حق الإنسانه لهندان في الحياة من خلال التعاون المشترك بين المواطنين والأحزاب السياسية.

$$
\text { المجلد الحادي والاربعون الجزء الثالث، مارس ^| • ب }
$$


ومن أهم هذه المشكلات البيئية مشكلة العشوائيات في مصر حيث بعانى هؤلاء السكان من مشاكل عديدة منها مشكلة التلوث والضوضاء والقمامة والأمية والتعليم والتتجير والصرف الصحي والمياه، ولمواجهة هذه المشكلات لابد من تضافر الجهود بين جميع الجهات المعنية لتحقيق التطوير الكامل لهذه المناطق ليس فقط عمرانبا ولكن أيضا إجنماعيا ونقافيا وسياسيا وإنسانيا حرصا على إنقاذ جيل جديد يقطن تلك العشوائيات من مختلف الأمراض الإجنماعية.

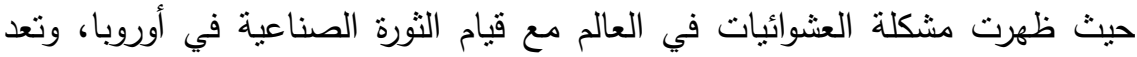
العشوائيات في مصر قضية أمن قومي ومواجهاتها مسؤولية قومية على الجهد الجماعي

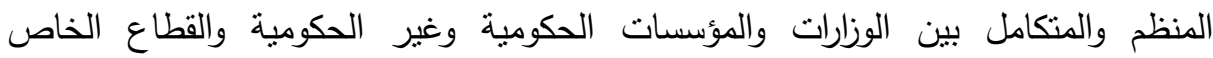

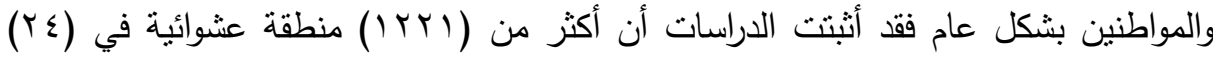
محافظة على التراب المصري يسكنها شعب تشير الثقديرات إلى أن تعداده قد يصل إلى منى

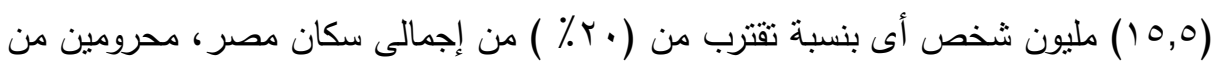

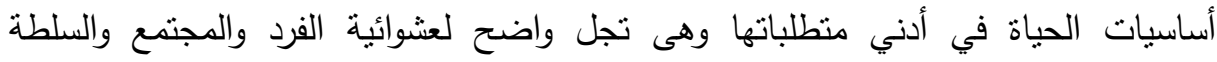

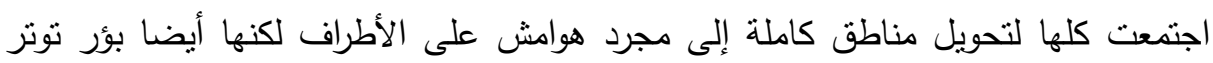
دائمة وقنابل موقوتة توشك على الإنفجار .

فمعظم سكان هذه المناطق هم ممن هاجروا من المناطق الريفية بحثاً عن حياة اعتقدوا

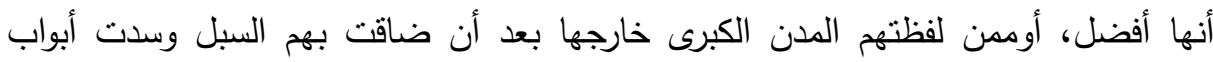
الحباة الكريمة في وجوههم، فانتشروا في الضواحي يبنون بعشوائية وفيها عاثشوا وتعايشوا،

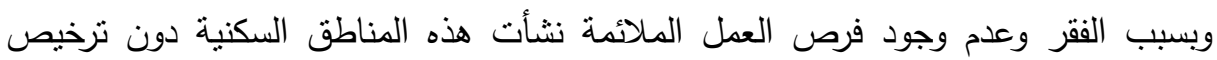
وتخطيط حكومي أوتخطيط عمراني بجوار المناطق الراقية يشكل خطر في ظل فل عدم إنشاء المرافق السكنية كالمياه والصرف الصحي والكهرباء. وعلى الأحزاب السياسية أن تقوم بدورها في تتمية سلوك المشاركة الثعبية لهذه المناطق

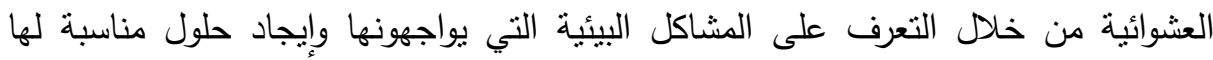
ووضع الخطط والبرامج في برامجهم السياسية وذللك من خلال المشاركة الشعبية سواء للأفراد أو للأحزاب السياسية التي هي اثد الحاجة لمشاركة هؤلاء السكان في أنشطتها المختلفة، فلابد لهذه الأحزاب من القيام بإحداث تغيرا حقيقا تشعر به سكان هذه المناطق العشوائية وتستقيد

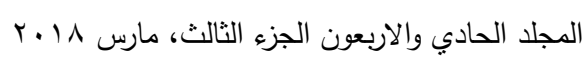


مجلة العلوم البيئية

معهز الدراسات والبحوث البيئية - جامعة عين شمس لهن

منه ويجذب للمشاركة في هذا التغيير لأنه بدون هذه المشاركة ستظل الأحزاب السياسية بمعزل عن الجماهير وتفقد شرعيتها.

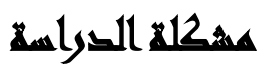

من خلال بعض الدراسات السابقة دراسة (حانم عبد المنعم أحمد). دراسة نطبيقية لدور الأحزاب السياسية في المشاركة الثعبية والعمل الإجتماعي لحماية البيئة. دراسة (أميرة كمال

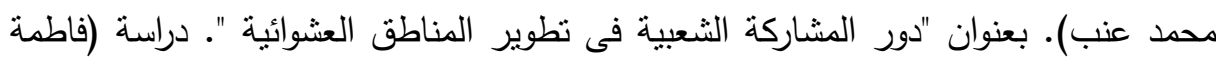

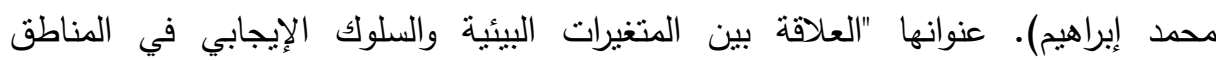
العشوائية". دراسة (ماجدة فؤاد). للمركز القومي للبحوث الإجتماعية والجنائية حول العشوائيات فى مصر • دراسة (بدرية شوقي عبد الوهاب وآخرون). بعنوان "البنية الإقتصادية والإجتماعية

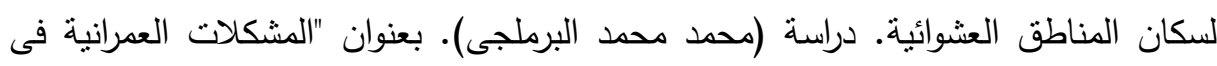

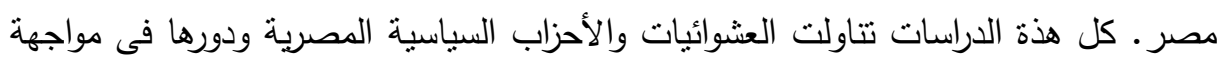

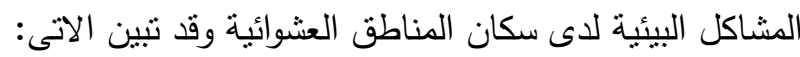
1-يعيش معظم سكان المناطق العشوائية فى مناطق يجب إزالتها أومناطق يقترح نطويرها وهى مناطق تعانى من إنعدام الخدمات والمرافق الأساسية.

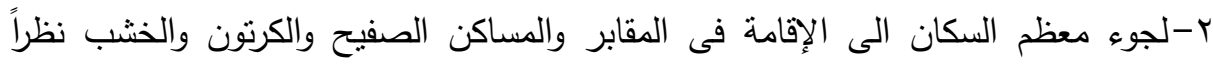
لتهدم منازلهم بسبب السيول وغيرها من عوامل الطبيعة أوبسبب الهجرة الريفية الحضارية.

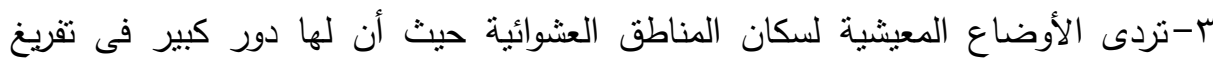

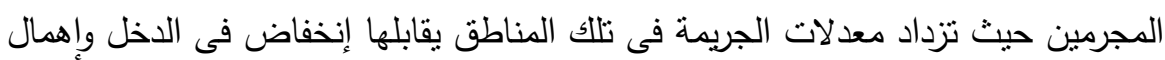
الخدمات الصحية والتعليم مما يجعلها مصدراً لتهديد الأمن القومى. ع- يعانى معظم المواطنين في مصر من المشكلات البيئية المختلفة المنتشرة في كافة الأرجاء وخاصة في المناطق العشوائية والتي تهدد هؤلاء المواطنين من حقوقهم في الحياة. ه-أن معظم المواطنين وخاصة في المناطق العشوائية لا يعرفون شيئًا عن الأحزاب السياسية الموجودة في مصر أوالخدمات التي تقوم بها ومرجعها الأمية الثقافية.

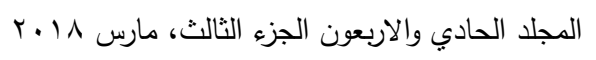


ج-ومعظم هؤلاء المواطنين عازفون عن المشاركة في أنشطة تلك الأحزاب السياسية وذلك لضعف الدور الذي تلعبه هذه الأحزاب في إثراء الحباة السياسية وعدم الإهتمام بالقضايا

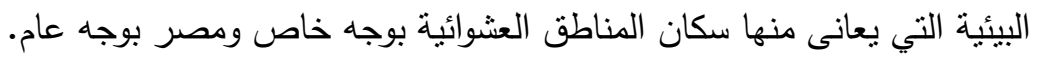

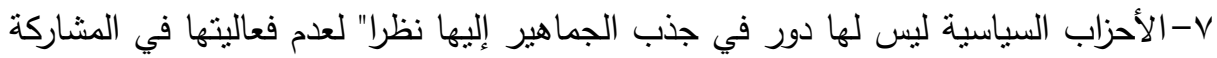

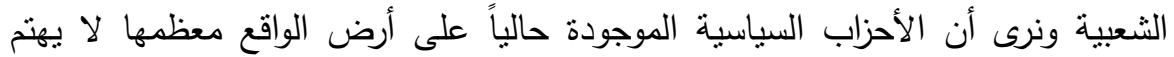
بقضايا البيئة المختلفة فلا يوجد سوى حزب أواثتان على الأكثر هما الذين اهتموا بقضايا

$$
\text { البيئة بشكل ضمني أوغير مباشر • }
$$

1- لا يتمتع أعضاء الأحزاب السياسية القدرة على جذب هبته هؤلاء السكان لها بفعل شخصيته أوقوة بياناته بل أنهم حريصون على رئاسة هذه الأحزاب من باب الوجاهة السياسية فحسب، مما جعلهم بعيدون عن المشاكل البيئية الحقيقة التي تواجه تلاك المناطق

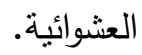

ولذلك على الأحزاب السياسية دور رئيسي في تتمية سلوك المشاركة الثعبية بالتثقيف وتتمية الذات نحوسلوك ايجابي للمشاركة وتأهيلهم بنشر الوعي البيئي بين هؤلاء المواطنين

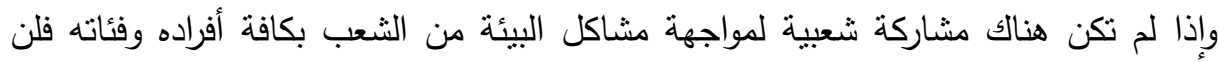
تحل نلك المشاكل، ومن هنا يتضح حاجة الأحزاب السياسية للمشاركة الثعبية في مجال البيئة

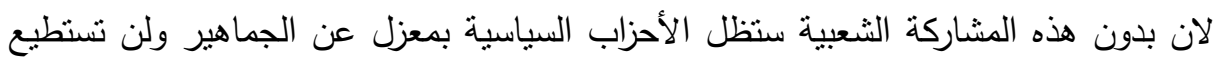
تلك الأحزاب أن تؤثر في الجماهير أوتعبر عنها ومن هنا تفقد الأحزاب السياسية شرعيتها

$$
\text { ومبررات وجودها. }
$$

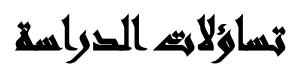

التساؤل الرئيسي: ما دور الأحزاب السياسية المصرية في تتمية سلوك المشاركة الثعبية لمواجهة بعض المشكلات البيئية لدى سكان المناطق العشوائية؟ 
1-ما دور الأحزاب السياسية المصرية في مواجهة المشكلات البيئية في المناطق العشوائية؟ r-ما البرامج والسياسات التي تضعها الأحزاب السياسية لتتيح لسكان المناطق العشوائية التئية تتمية سلوك المشاركة لمواجهة المشكلات البيئة؛ r-هل تتيح الأحزاب السياسية الفرص لسكان المناطق العشوائية التدريب على أساليب حل

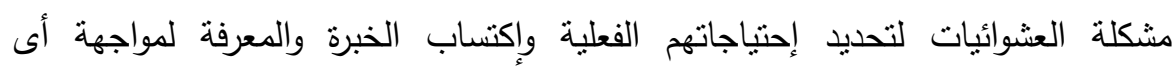
مشكلات أوعقبات بيئية تواجهرج؟ ع-ما المشاكل البيئية التي يعانى منها سكان المناطق العشوائية وكيفية التغلب عليها ودور الأحزاب السياسية وسكان هذه المناطق لمواجهة وحل هذه المشكلات؟

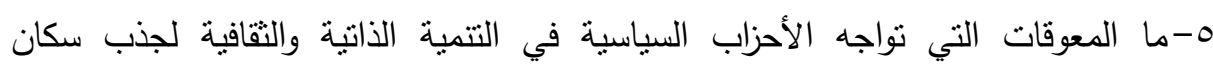
المناطق العشوائية في المشاركة الثعبية لمواجهة مشكلاتهم البيئية؟ الثراب

\section{أهساهنب التراسما}

لكل دراسة هدف تسعى لتحقيقه وتسعى هذه الدراسة إلى التعرف على دور الأحزاب

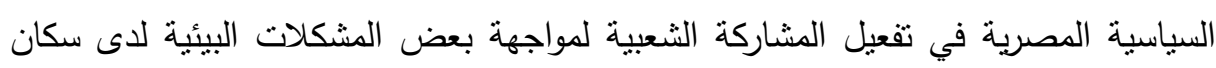

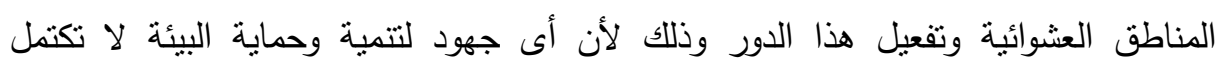

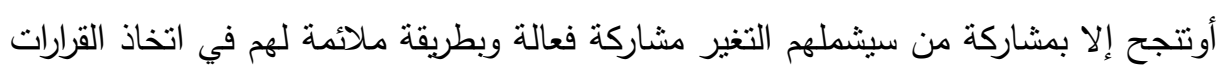
التي تتعلق بالخدمات التي ستؤدى لهم ومشاركتهم في حل مشكلاتهم البيئية.

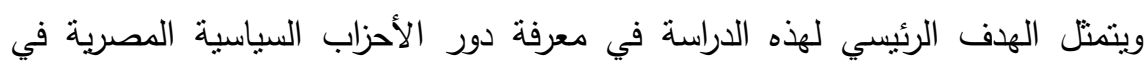
تفعيل المشاركة الثعبية لمواجهة بعض المشكلات البيئية لاى سكان المناطق العشوائية.

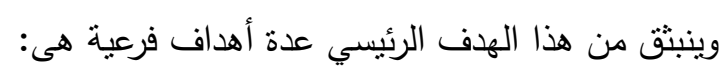

1- التعرف على دور الأحزاب السياسية في مواجهة المشكلات البيئية منل (التلوث - القمامة - سلوكيات بعض الثباب - التتجير - الصرف الصحي - المياه) في المناطق فئل العشوائية. 
r-معرفة البرامج والسياسات التي تضعها الأحزاب السياسية لنتيح لسكان المناطق العشوائية في المشاركة لمواجهة المشكلات البيئية.

r-التعرف على مدى إتاحة الأحزاب السياسية الفرص لسكان المناطق العشوائية في المشاركة الثعبية لتحديد إحتباجاتهم الفعلية لإكتساب الخبرة والمعرفة لمواجهة أى مشكلات أوعقبات

$$
\text { في المستقبل. }
$$

ع-معرفة المشكلات البيئية التي يعانى منها سكان المناطق العشوائية وكيفية التغلب عليها

$$
\text { ودور الأحزاب السياسية لمواجهة وحل هذه الشككلات البيئية. }
$$

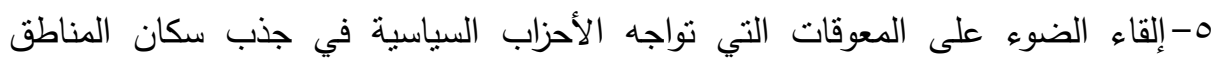

$$
\text { العشوائية في المشاركة الثعبية لمواجهة مشكلاتهم البيئية. }
$$

1-الكثف عن مدى إستجابة سكان المناطق العشوائية ومشاركتها في مواجهة مشكلات البيئة

$$
\text { من وجهة نظر الأحزاب السياسية. }
$$

V-التعرف على قدرة سكان المناطق العشوائية في التعامل مع المشكلات الخاصة بهر وإثباع التشاع إحتياجاتهم لتتمية المجتمع وحل مشاكلهم البيئية.

\section{أهمية الصراسمة}

$$
\text { 1- أنحدد أهمية الدراسة من خلال ما يلى من أهمية تفعيل دور الأحزاب السياسية في مواجهة المشكلات البيئية. }
$$
r-محاولة تتمية سلوك ساكني العشوائيات نحوالمشاركة في مواجهة المشكلات بالتعاون مع معرد

$$
\text { الأحزاب السياسية. }
$$

r-تعتبر الأحزاب السياسية في حاجة لتفعيل المشاركة الثعبية لتنبى مشروعات البيئة لاى

$$
\text { سكان المناطق العشوائية. }
$$

ع-محاولة نشر الوعي البيئي لدى سكان المناطق العشوائية بدور الأحزاب السياسية وأهم الخدمات البيئية التي تقدمها وإيجاد حلول مناسبة لمشكلاتهم.

ه-أهمية مشاركة سكان المناطق العشوائية في عملية إنخاذ القرارات التي تهنم بمشاكل البيئة ومحاولة التخطيط لحل تلك المشكلات.

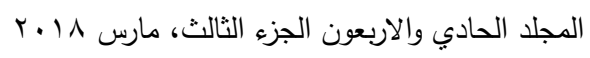


مجلة العلوم البيئية

معهز الدراسات والبحوث البيئية - جامعة عين شمس لهن

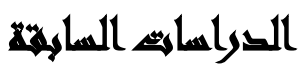

هناك العديد من الدراسات والتراث الذى تتاول مشكلة العشوائيات بغزارة، ولكن لا يوجد

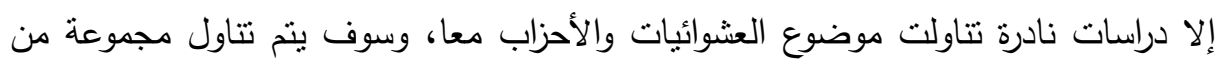
الدراسات النى تعرضت لموضوع الدراسة، وذلك على النحو النالى:

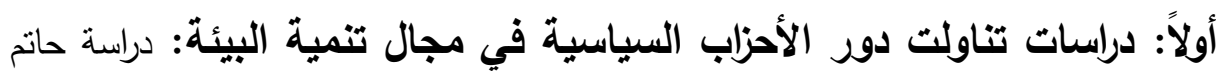

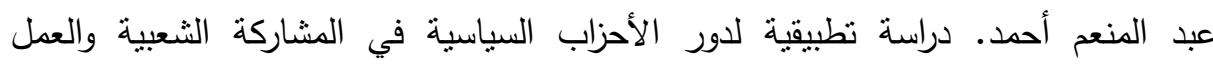

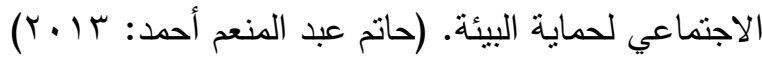

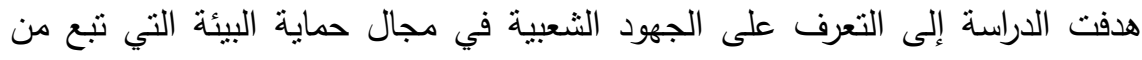

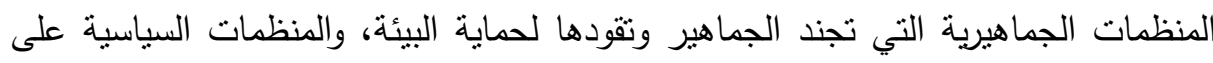

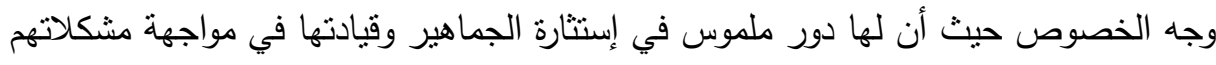

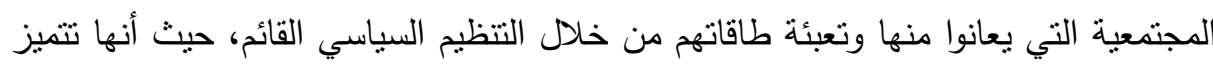

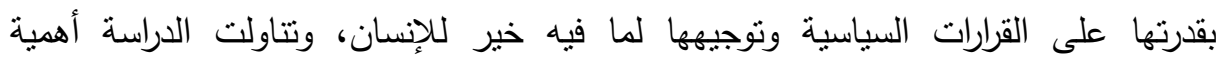

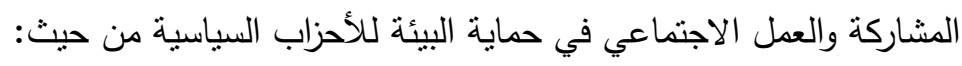

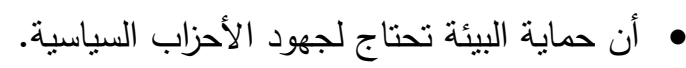
• • أن الأحزاب السياسية في حاجة لتنبى دعوة حماية البيئة.

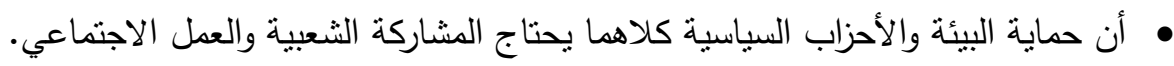

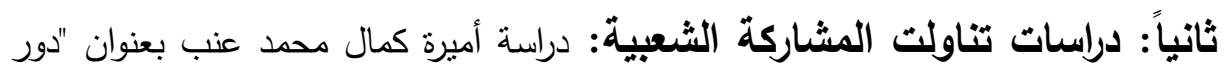

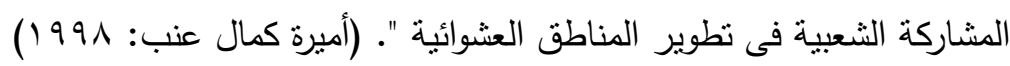

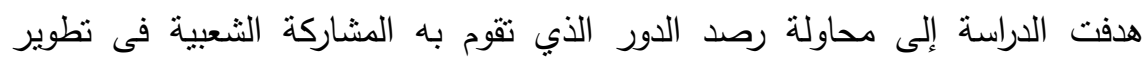

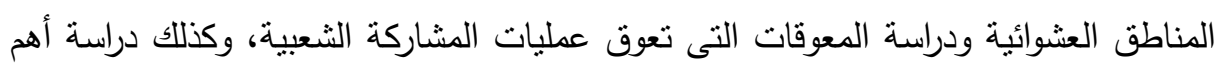

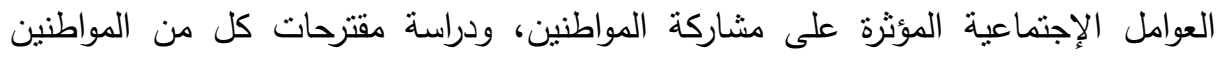

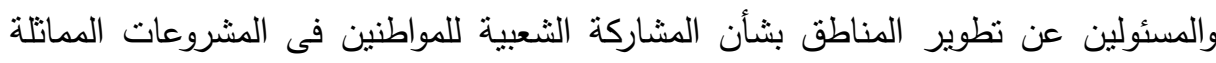
مستقبلا"، واستخدت الباحثة منهج المسح الاجتماعي عن طريق العينة. 
وأوضحت الدراسة إختلاف درجة إستجابة مشاركة المواطنين تبعا لعدة عوامل منها نفسي

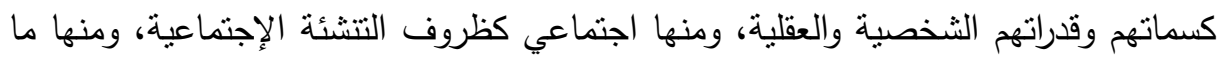
هو إقتصادي أو سياسي أو تربوي وهذا ما ينتج عنه إختلاف مشاركة المواطنين. وأن

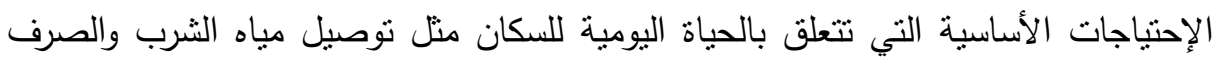
الصحي والكهرباء لها الأولوية فى مشاركة المواطنين. ثالثاً: دراسات تناولت ظاهرة العشوائيات: دراسة فاطمة محمد إبراهيم، عنوانها "العلاقة بين المتغيرات البيئية والسلوك الإيجابي في هي

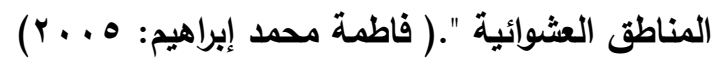
هدفت الدراسة إلى التعرف على العلاقة بين متغيرات البيئة الفيزيقية ومتغيرات البيئة

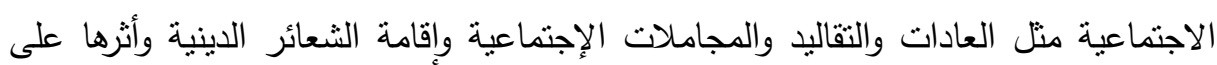
السلوك الإيجابي لقاطني المناطق العشوائية. دراسة ماجدة فؤاد. للمركز القومي للبحوث الإجتماعية والجنائية حول العشوائيات فى مصرك .

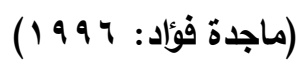

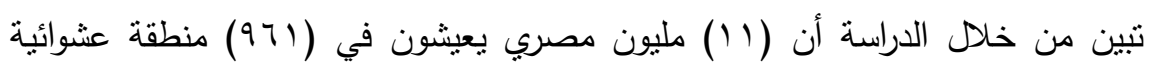

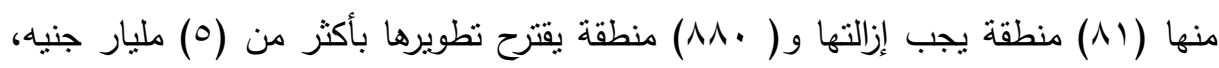
بعدما ربطت بين تردى الأوضاع المعيشية لسكانها، وتفريغ الخارجين عن القانون.

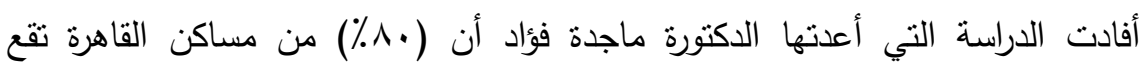

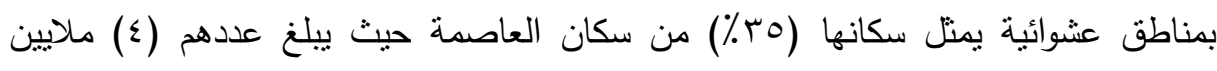

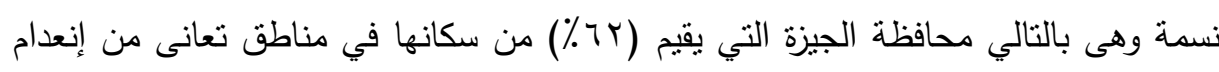

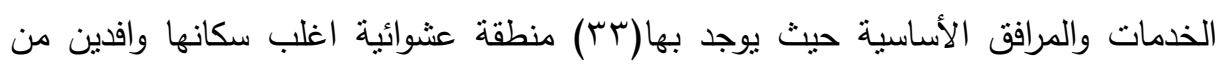
الصعيد. وأوضحت الدراسة أن كثثر من المواطنين قد لجئوا إلى الإقامة بالمقابر والمساكن

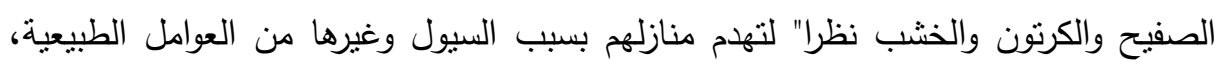

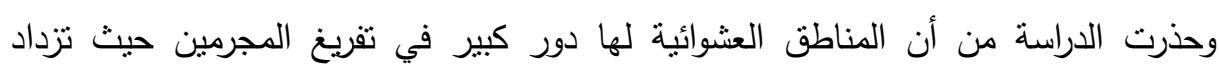

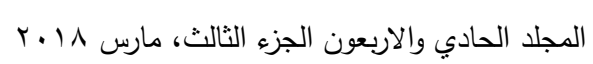


معدلات الجريمة في تلك المناطق يقابلها إنخفاض في الدخل وإهمال في الخدمات الصحية والتعليم.

رابعًا: دراسات تناولت الآثار الاجتماعية والاقتصادية للعشوائيات: دراسة بدرية شوقي عبد الوهاب وآخرون: بعنوان " البنية الإقتصادية والإجتماعية لسكان

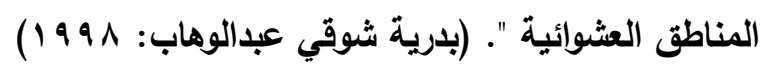
فرضت المناطق العشوائية نفسها على المجتمع وأثارت ظاهرة جديدة بالدراسة والتحليل

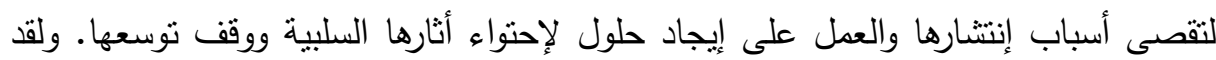

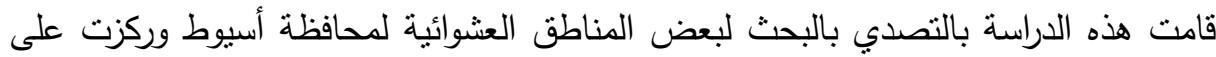

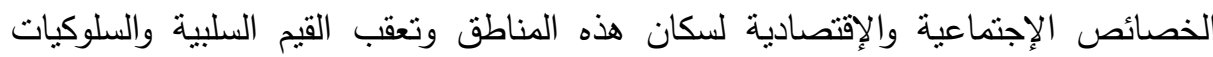
المنحرفة في منطقتين عشوائيتين بمحافظة أسيوط هما منطقة الوالدية ومنطقة غرب المدابغ. خامسًا: دراسات تناولت تطوير وتنمية العثوائيات: دراسة محمد محمد البرملجى: بعنوان "المشكلات العمرانية فى مصر" (محمد محمد

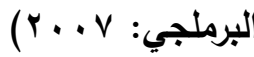

يحاول هنا البحث التصدي إلى مشكلة من أكبر المشكلات العمرانية في مصر في العصر الحديث وهى مشكلة إنتشار العشوائيات على كافة أنحاء الجمهورية وخاصة حول المدن الكبرى مما تسبب عنة العديد من السلبيات في مختلف المجالات الإجتماعية والصحية والإقتصادية والعمرانية وبركز البحث على رصد وتحليل أبعاد تلك المشكلة.

\section{التعليق على الاراسات السابقة:}

استفاد الباحث من الدراسات السابقة التى عرضها، وذلك على النحو التالى: ا-من دراسة جانتسوس إيرين الين "المشاركة الشعبية في التخطيط البلدي للتتمية في بولوفيا،

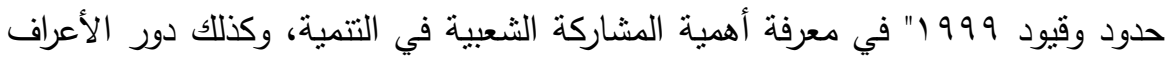
والممارسات الحياتية في التوصل إلى قرارات سليمة بشأن التخطبط والتتمية. 
Y-وكذلك من دراسة أميرة كمال عنب 1991 "دور المشاركة الثعبية فى نطوير المناطق العشوائية. في دراسة صور المشاركة الشعبية فى عملية التطوير والتتمية، وكذللك الوقوف

$$
\text { على أهم العوامل الإجتماعية المؤثرة على مشاركة المواطنين. }
$$

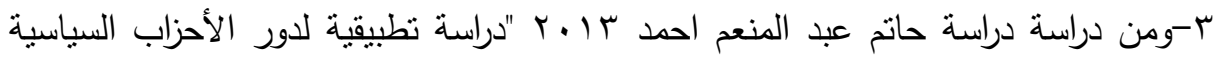
في المشاركة الشعبية والعمل الإجتماعي لحماية البيئة" فى التعرف على الجهود الثعبية في مجال حماية البيئة التي تتبع من المنظمات الجماهيرية التي تجند الجماهير وتقودها

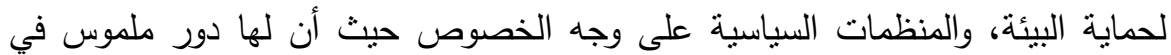
إستثارة الجماهير وقيادتها في مواجهة مشكلاتهم المجتمعية التي يعانوا منها وتعبئة طاقاتهم من خلال التنظيم السياسي القائم.

ع -ومن دراسة محمد رجب أحمد "دور الأحزاب السياسية في التتمية والبيئة - دراسة لبرامج الأحزاب السياسية المصرية" فى التعرف على الدور الذى تقوم به الأحزاب في مجال

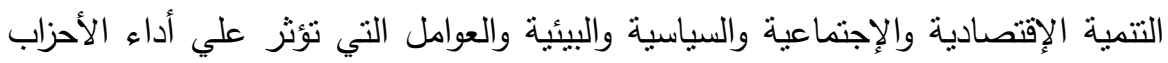

$$
\text { السياسية لدورها المتوقع في مجال التتمية والبيئة. }
$$

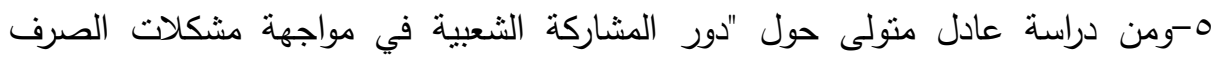

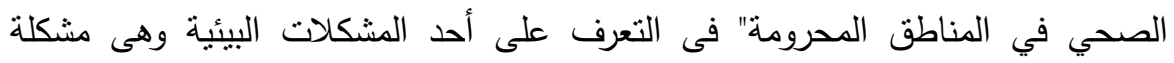

$$
\text { الصرف الصحي ومحاولة معرفة دور الجهود الثعبية في مواجهتها. }
$$

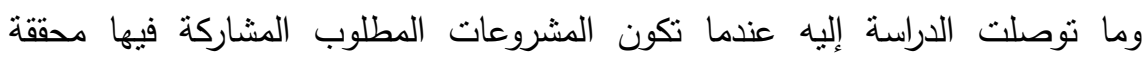
لإحتياجات الأفراد وتعكس رغباتهم وإتجاهاتهم نحوالتطوير زادت مشاركة الأفراد فيها، وكذلك تتاسب قدرة القيادات الموجودة بالمنطقة على إقناع المواطنين بأهمية المشروع وإستنثارة

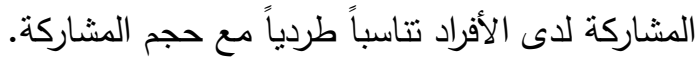

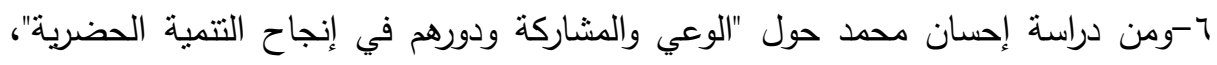
والتى كان من أهم أهدافها التعرف علي الدور الذي تلعبه المؤسسات التظيمية في تشكيل

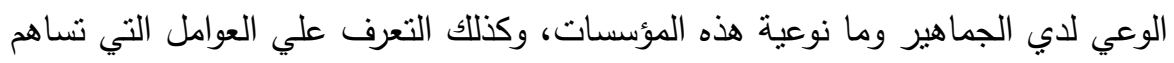
في إنجاح التتمية الحضرية. وكانت أهم نتائج تلك الدراسة أهمية الدور التي توكية تلعبه

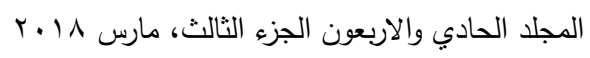


مجلة العلوم البيئية

معهد الدراسات والبحوث البيئية - جامعة عين شمس ليه

المؤسسات التتظيمية في نتكيل الوعي لدي الجماهير ومن أهم هذه المؤسسات: المؤسسات التعليمة، المؤسسات الإعلامية.

V-ومن دراسة فاطمة محمد إبراهيم حول "العلاقة بين المتغيرات البيئية والسلوك الإيجابي في البعات المناطق العشوائية"، وذلك بالتعرف على العلاقة بين متغيرات البيئة الفيزيقية ومتغيرات البيئة الإجتماعية مثل العادات والتقاليد والمجاملات الإجتماعية وإقامة الشعائر الدينية وأثرها على السلوك الإيجابي لقاطني المناطق العثوائية.

^-ومن دراسة للمركز القومي للبحوث الإجتماعية والجنائية حول العشوائيات فى مصر في في الإئي التعرف على أن كثير من المواطنين قد لجئوا إلى الإقامة بالمقابر والمساكن الصفيح

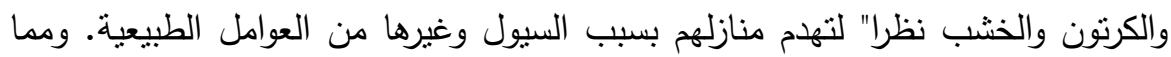
حذرت الدراسة من إن المناطق العشوائية لها دور كبير في تفريغ المجرمين حيث تزداد معدلات الجريمة في تلك المناطق يقابلها إنخفاض في الدخل وإهمال في الخدمات

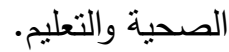

9-ومن دراسة إيمان جال فى التعرف على إن إرتفاع معدلات الزيادة الطبيعية للسكان تعد

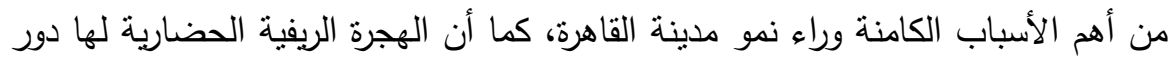
هام في نمو المدينة وكذلك العامل الإقتصادي له دور هام كعامل من عوامل الطرد من من لهن

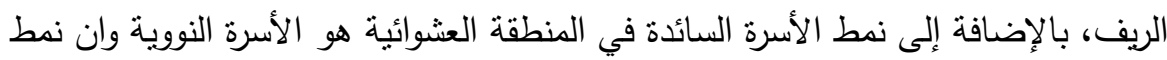
الإسكان الريفي هو السائد في المنطقة، إلى جانب إفتقار المنطقة للخدمات والمرافق

• أومن دراسة بدرية شوقي عبد الوهاب وآخرون فى التعرف على الخصائص الإجتماعية

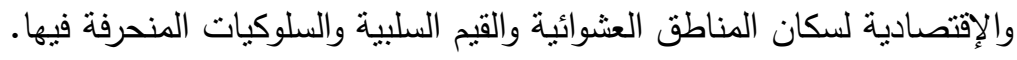

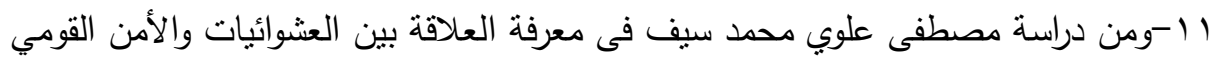
من خلال بعدين يتمنل الأول في كون العشوائيات مصدراً لتهديد الأمن القومي، والبعد

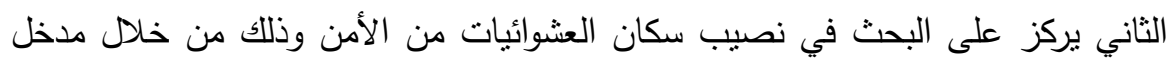

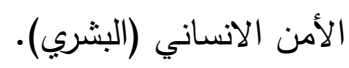


rا-ومن دراسة جمال محمود حامد فى التعرف على مبادره مدن بلا أحياء عشوائية في 1 أجمعت حكومات العالم على ضرورة التخلص التدريجي من المناطق العشوائية وتحسين مستوى معيشة سكانها.

النظريات المرتبطة بالدراسة: سوف ينم تتاول فيما يلى بعض النظريات التى تعرضت لموضوعات خاصة بالدراسة، وذللك على النحو التالى: أولاً: النظريات العلمية المفسرة لنشأة الأحزاب السياسية بوجه عالفية عام: الحياة السياسية قديمة، والصراع السياسي ظهر منذ أن وجد الإنسان فى شكل جماعات، حيث أن لكل إنسان آماله

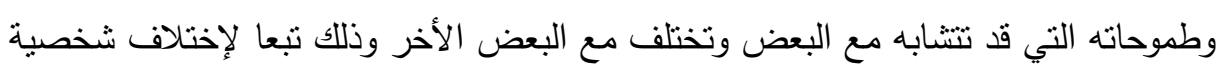
كل فرد وبيئته الفيزيقية والإجتماعية. 1- نظرية الدور: يعتمد هذا الموضوع على نظرية الدور كإطار مرجعي، لان هذه النظرية

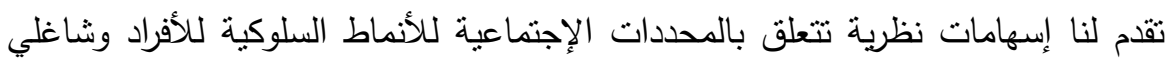
المراكز الإجتماعية، كما أنها في نفس الوقت تقدم لنا مجموعة من المفاهيم التي تساعدنا

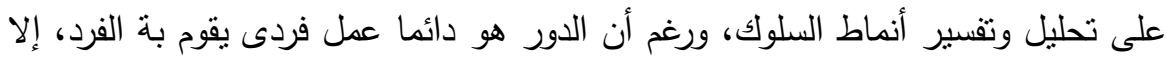
أن أعمال أى جماعة تحدث دائما عن طريق مجموعة من الأدوار المرتبطة فيعتبر الدور

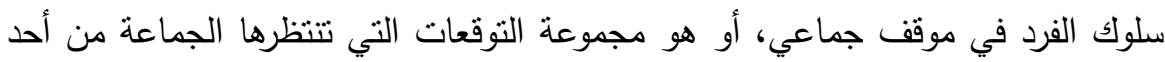

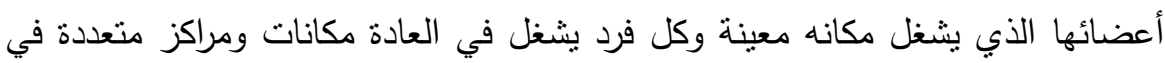
نفس الوقت، ولذلك فهو يقوم بأدوار متعددة.

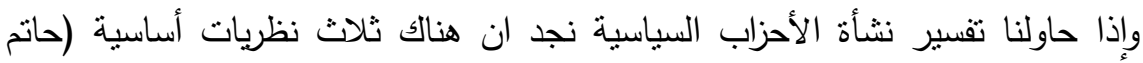
عبد المنعم احمد، ب ا • (Y) تقسر لنا ذللك وهى: أ- النظرية التقليدية (البرلمانية). ب- نظرية الأزمات (الموقف التاريخي). ج- نظرية التحديث. 
ثانيًا: نظريات مرتبطة بتعديل السلوك البيئى: النظرية السلوكية: Behavioral theory : يتركز إهتمام النظرية السلوكية حول التغيير في

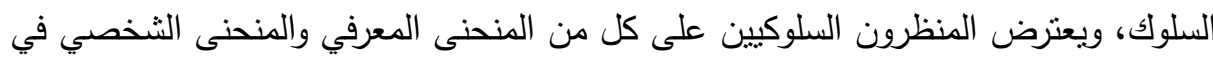
مجال إحداث تغيير في إتجاهات الفرد وقيمة. ويركز أصحاب هذا المنحنى على أثنكال

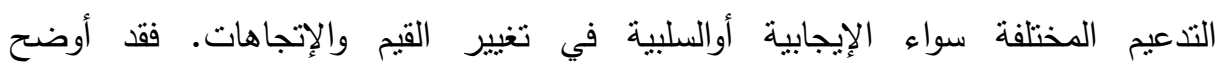
ماكينى ( Mckinney) أن برامج تغيير القيم يجب أن تتركز على كلا" من التذعيم والتوجه السلوكي (الأمر أو النهي). وهناك بعض الإتجاهات التي تؤكد على أهمية التغيير المعرفي، وأخرى نؤكد على أهمية

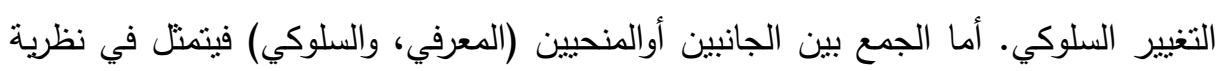
التغيير المعرفي السلوكي، التي قدمها "ملتون روكيش". النظرية المعرفية - السلوكية: Atheory of cognitive and behavioral تعد المعرفة هي إنتاج إجتماعي لنشاط الناس في المجتمع وهى الني تحقق التواصل بين أفراد المجتمع من خلال إتفاقهم على معناها، وقبولها لحقيقتها. (عادل السكري: 999 (1) )

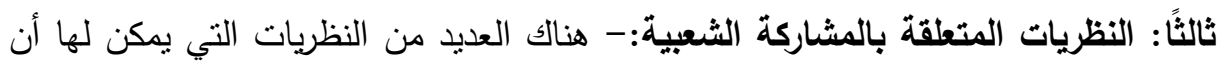
تفسر وسائل جذب المواطنين للمشاركة. نظرية التبادل والتفاعل الاجتماعي:وتتشير إلى "تبادل المنفعة بين المواطنين والمنظمة هي العامل الحاسم للمشاركة سواء كانت تلك المنفعة إقتصادية أو إجتماعية أو نفسية، (Peter.

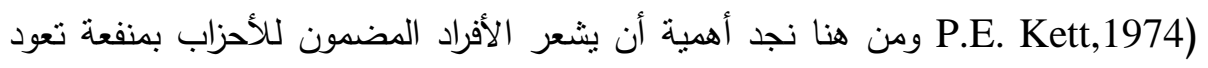

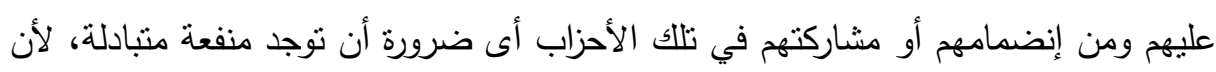
أى فرد يحتاج إلى أثنياء لدى الآخرين وفى نفس الوقت لدية أنشياء يرغب فيها فئا الآخرين.

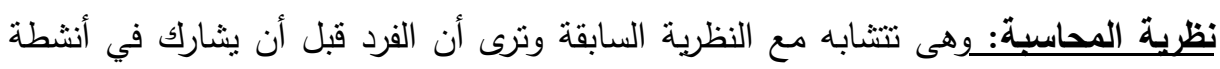

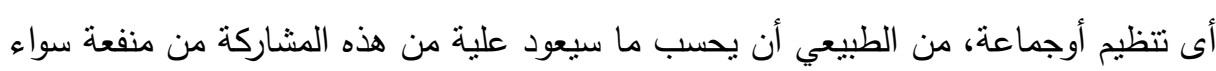

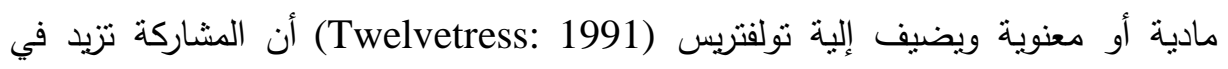


قدري محمود حفني وآخرون

المواقف التي يعرف الناس عنها الكثبر، فكلما عرف الناس معلومات كثيرة عن المواقف المطلوب فيها المشاركة زادت مشاركتهم فيها. النظرية المعيارية:_وترى هذه النظرية أن المشاركة تتم في إطار الضبط الاجتماعي، فعندما يرى الأفراد أن المشاركة مفيدة للجميع وللمجتمع بوجه عام، فهذا بدفع الأفراد إلى المشاركة.

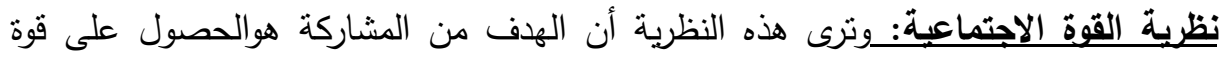

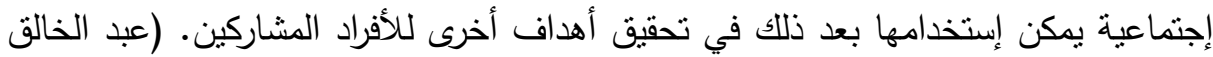
عفيفي: بو (199) رابعًا: النظريات المفسرة لعدم المشاركة: هناك بعض النظريات التي تتاولت بالثرح والتحليل عدم المشاركة ومن هذه النظريات: نظرية الاغتراب: برى فروم (Fromm) أن الإنسان يحاول الفرار من احساسه بالوحدة بالإرتباط بالحياة حوله، وإذا فنثل في ذلك فان احساسه بالوحدة بعنى عدم نجاحه في الإرتباط

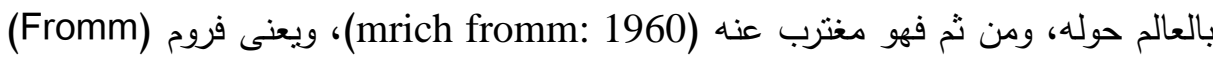
بالإغتراب بأنه إحساس الفرد بأنه غريب عن نفسه وذب وذاته، وبالتالي تصبح أفعاله ونتائجه سيئة،

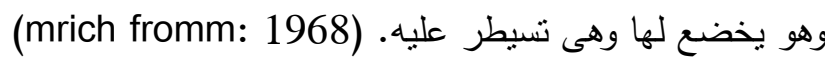
خامسًا: النظريات المفسرة لنشأة المناطق العشوائية: لقد تعددت المداخل الماتل والإتجاهات والنظريات الني حاولت تفسير نشأة المناطق العشوائية ومن هذه النظريات: (السيد محمد

أ- نظرية الدوائر متعددة المراكز:وتستتد هذه النظرية علي فكره مؤداه اي بناء داخلي للمدينة

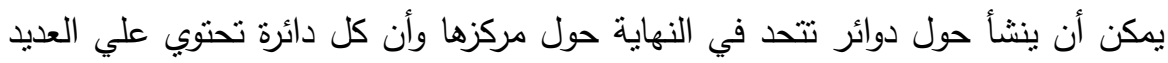

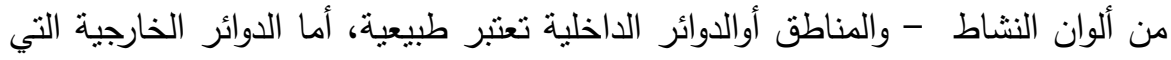
تخرج عن زمام المدينة فتسمى بالمناطق المتخلفة وهذه المناطق تتشأ بطريقة عشوائية

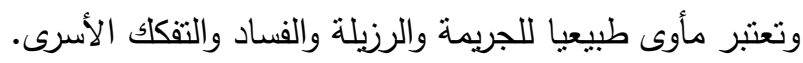
ب- نظرية القطاعات:وهى التي يتم من خلالها تحديد النمط الإيكولوجي للمدينة وتقوم هذه ولهي النظرية على التقسيم المبنى على سعر الأرض الذي يقسم المدينة إلى ثلاث قطاعات: 
• قطاع الإيجارات المنخفضة: يسكنها العمال ذوى الدخول المنخفضة.

• قطاع الإيجارات المتوسطة: يسكنها العمال ذوى الدخول المتوسطة.

• • قطاع الإيجارات العالية: يسكنها الأغنياء.

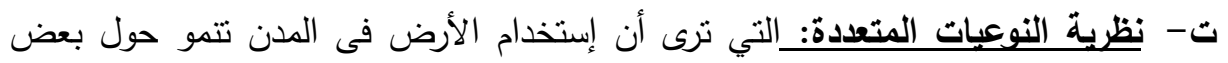
النوايات المتجزأه. وتتباين المناطق الرئيسية داخلها.

ويمكن القول أن النطورات الإقتصادية والإجتماعية تسمح بوجود نوعين من النمو لونين السكنى أولها هو النمو السكنى العشوائي التراكمي الذي يقام دون خطة موضوعة لمله الأرض الفضاء داخل حدود المدينة، أو إقامة المباني عند أطرافها ويتكون السكن من عنش بهري

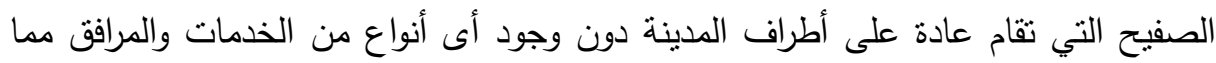
ينتج عنة الكثير من الأمراض، والظروف الاجتماعية والاقتصادية السيئة. أما النوع الثاني فيقام عندما توجد نواة عمرانية جديدة تحاول الإنفصال عن إحدى المدن القديمة نتيجة لعمليات الإنفصال العرفي أو نتيجة التمييزات الإجتماعية.

\section{هخاهمبر الدوراسة}

يعتبر تحديد المفاهيم والمصطلحات العلمية أمراً ضرورياً فى البحث العلمى بوجه عام،

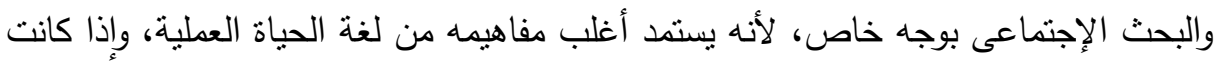
العلوم الطبيعية قد قطعت شوطاً كبيراً فى هذا المجال، بحيث نجد أن هناك شبه إتفاق بين العلماء يتعلق بالمصطلحات التى يستخدمونها فى علومهم، فأن الوضع يختلف فى العلوم

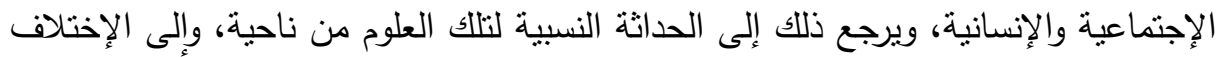
الذى يصل إلى حد التتاقض أحيانا بين المنطلقات والأطر التصورية التى يرتكز عليها العلماء والباحثتن الإجنماعيون فى دراستهم من ناحية أخرى. مفهوم الأحزاب السياسية: مفهوم الحزب في علم الإجتماع والسياسة: من وجهة نظر علماء الإجتماع بأنه جماعة من الأفراد تتشرك في تصور واحد لبعض المسائل السياسية، وتكون رأي انتخابياً واحداً. 
من وجهة نظر علماء السياسة بأنه إتحاد أو تجمع من الأفراد ذي بناء تتظيمي على المستوبين القومي والمحلى يعبر عن جوهرة عن مصالح قوى إجتماعية محددة، ويستهدف الوصول إلى السلطة أوالتأثير عليها، بواسطة أنشطة متعددة خصوصنا" من خلال تولى ممنليه

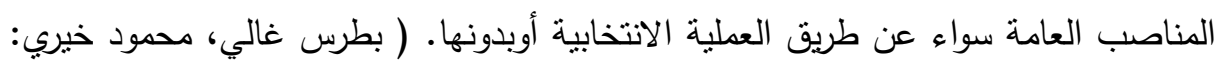

وبناءً على العرض التحليلى السابق فأنه يمكن للباحث ان يتبنى تعريفاً إجرائياً لمفهوم الحزب: "الحزب هو مجموعة من الأفراد تشترك فى تصور واحد لبعض القضايا والمشكلات بربطهم مبادىء وفكر ومصالح وأصول مشتركة، تتعاون معا" للوصول للحكم بغرض تلتفيذ برنامجها ومبادئها من خلال مرشحيها فى الإنتخابات، التى تقوم بإختبارهم وإعدادهم سياسياً

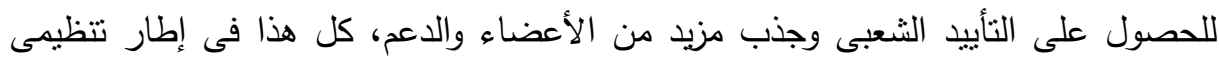
معين يعمل على المستويين المحلى والقومى، والحزبى هو أى فرد منضم لأى حزب من من الاعناه

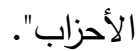

مفهوم السلوك: السلوك الإنسانى منتوع ومتغير ومنطور وشديد التعقيد ويعبر عن جميع أوجه النشاط الفعلي والحركي والإنفعالي الذي يقوم به الفرد لكي يتوافق ويتكيف ويتعايش مع بيئته وهو ينقسم إلى سلوك فطرى يولا به الإنسان، وسلوك يكنسب من خلال احتكاكه بالبيئة

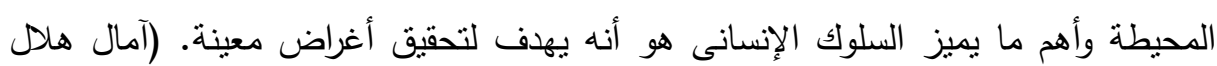

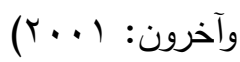
مفهوم البيئة: أن تحديد مفهوم البيئة لبس يسيراً كما يتصور البعض، حيث تتعدد الدفاهيم بإختلاف البحث في كل فرع من فروع العلوم الإجتماعية، فكل منهم يعرف البيئة وفقاً لرؤيته

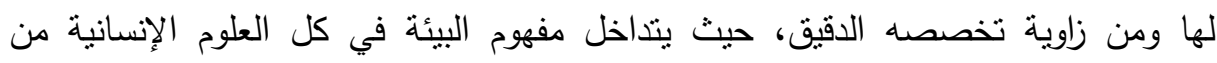
اجتماع وجغرافيا وإقتصاد وغير ذللك، فقد بات الحديث عن البيئة الإجتماعية، والبيئة الجغرافية، والبيئة الإقتصادية، بعد أن كان الحديث مقصوراً في البداية على البيئة المعمارية.

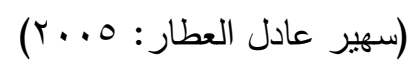


وبناءً على العرض التحليلى السابق فأنه يمكن للباحث أن يتبنى تعريفاً اجرائياً لمفهوم

هي الإطار الفيزيقي والإجتماعي الذي يعيش فيه الفرد بما يتضمنه من تكنولوجيا يخترعها الإنسان، وهذا الإطار يتأثر بكل التفاعلات والعلاقات القائمة بين جميع العناصر ، الإني وينعكس ذللك علي سلوك وإتجاهات وقيم الفرد من مختلف جوانب حياته، ومن ثم فالبيئة ديناميكة تختلف من مكان لأخر ومن زمان لأخر .ولذلك لكل فرد بيئته الخاصة به.

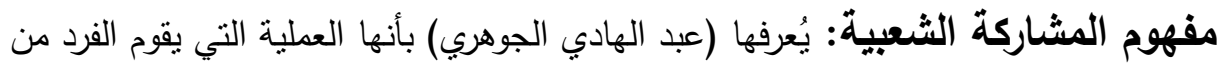
خلالها بالإسهام الحر الواعي في صياغة نمط الحياة لمجتمعة في النواحي الإقتصادية

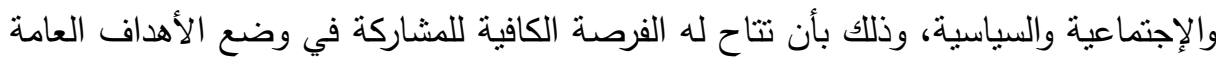
لحركة المجتمع وتصور أفضل الوسائل لتحقيق هذه الأهداف، وتحديد دورة في أنجاز المهام اليومية التي تتجمع على المستوى القومي في صورة أهداف عامة يكون الفرد مقتتعاً بها،

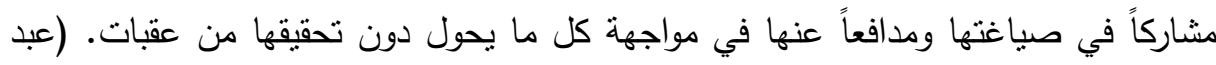

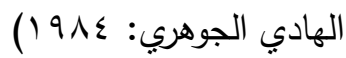
وبناءً على العرض التحليلى السابق فأنه يمكن للباحث أن ينبنى تعريفاً اجرائياً لمفهوم

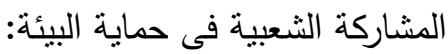
المشاركة فى حماية البيئة هى الوسيلة التى يتمكن بها أعضاء الحزبه من التأثير الإيجابى فى القرارات والسياسات التى تتصل ببيئتهم استتادا الى مبدأ الديموقراطية الذى يعطى لئى

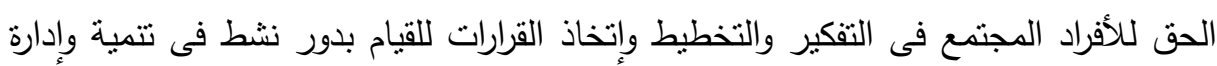
الخدمات المتعلقة ببيئتهم والتى تؤثر على حياة أفراد المجتمع مع متابعة وتقييم هذه الخدمات. مفهوم المناطق العشوائية: ويُعرف (ممدوح الوالي) المنطقة العشوائية بأنها منطقة لا لاني

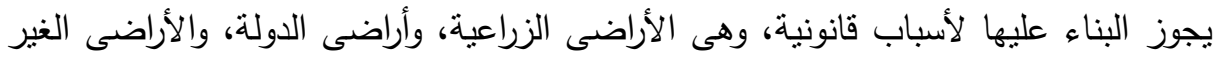

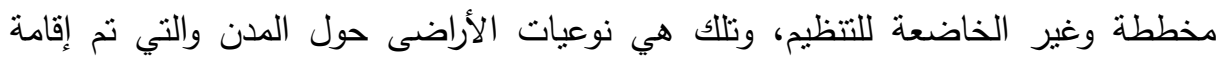
المناطق العشوائية عليها وحيث أنها مناطق أقيمت مخالفة للقوانين فأن الجهات المسئولة التهات ترفض أن تمدها بالخدمات كمياه الثرب والصرف الصحي والكهرباء، كذلك لم ينت بناء

$$
\text { المجلد الحادي والاربعون الجزء الثالث، مارس ^| • ب }
$$


المدارس والمراكز الطبية بها، وبالتالي نشأت المناطق العشوائية غير مخططة أو منظمة وغير المستوفاة للنواحي الصحية كما تفقتر إلى الخدمات اللازمة لممارسة الحياة الطبيعية. (ممدوح

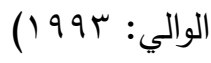

وبناءاً على العرض التحليلى السابق يتبنى الباحث التعريف الإجرائى للمناطق العشوائية:

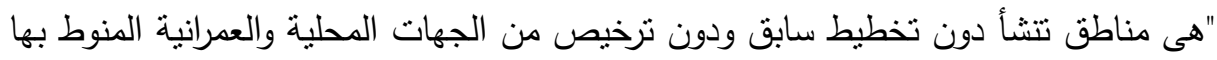

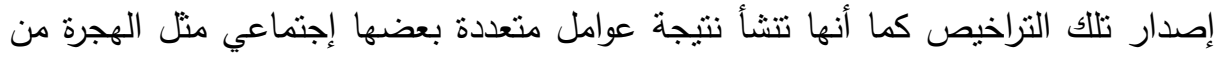
الريف إلى المدن وبعضها جغرافي منل الهروب من الجنوب الفقير والمحروم إلى الثمال الذى لهی يتمتع بكافة الخدمات الإقتصادية والإجتماعية والترفيهية وفرص العمل المتوافرة وبعضها بيولوجى وبعضها ثقافى له سمات ثقافية خاصة به (ثقافة الفقر). وكذلك فإن سكان وأفراد تلكا

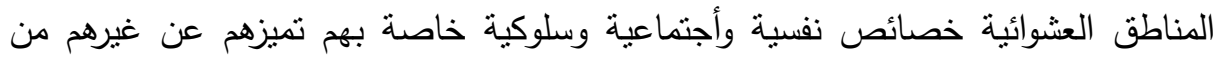
أفراد ذات المجتمع الذين يعيشون فيه.

\section{هنهمج التراسلة}

بناءاً على مشكلة الدراسة والقائمة على دراسة إتجاهات وآراء عينة عشوائية من أسر

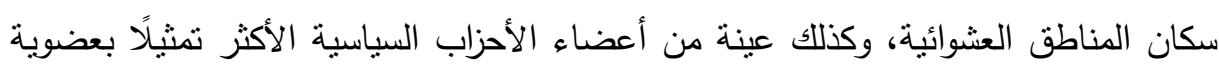

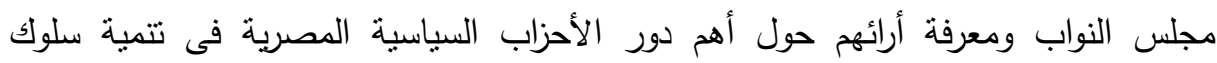
المشاركة الشعبية لمواجهة بعض المشكلات البيئية لدى سكان المناطق العشوائية. وقد نم تحديد المنهج الملائم للاراسة الحالية وهو المنهج الوصفي التحليلى لئلى ذلك لأن

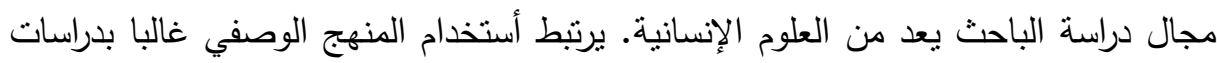
العلوم الإجتماعية والإنسانية والتي استخدمته منذ نشأته وظهوره.

\section{مجالايت التراسة}

المجال المكاني: تغطى الدراسة بعض المناطق العشوائية الموجودة في جمهورية مصر العربية (بولاق الدكرور - ميت عقبة - إمبابة). المجال البشرى: تمثل في عينتين: 
1- العينة الأولى تتمثل في أعضاء الأحزاب السياسية.

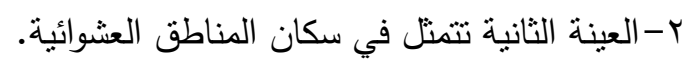
المجال الزمني: استغرقت الفترة التى نم فيها جمع البيانات الميدانية والتفريغ والإحصاء

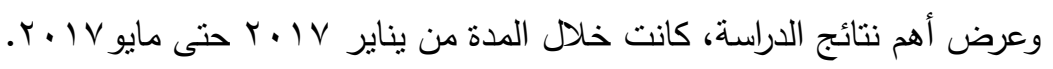

\section{هبraris}

يمثل مجتمع الدراسة عينة من الأسر التى تعيش فى مناطق عشوائية بمحافظة الجيزة فى

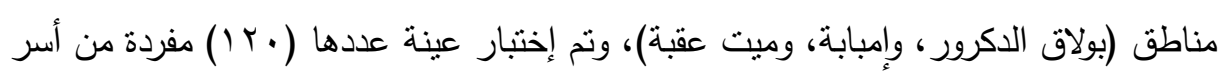

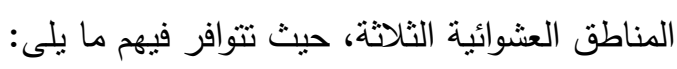

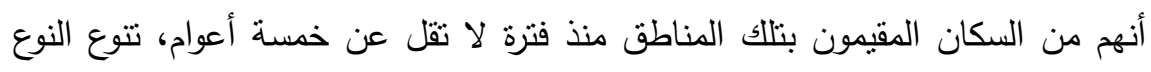

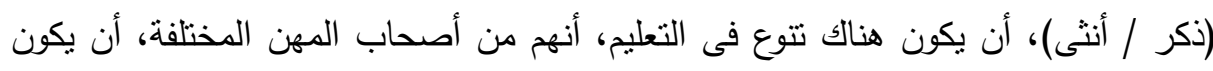
هناك تتوع فى المراحل العمرية. جدول( (1): نوزيع المبحوثين طبقا للنوع

\begin{tabular}{|c|c|c|}
\hline النسبة & التكرار & \\
\hline$\Gamma_{0,0}$ & $\varepsilon r$ & ذكر \\
\hline 70,0 & V^ & أنثى \\
\hline $1 \ldots$ & 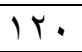 & المجموع \\
\hline
\end{tabular}

من الجدول رقم (1) الخاص بنوع مبحوثى الدراسة يتضح أن (Y) مبحوث بنسبة

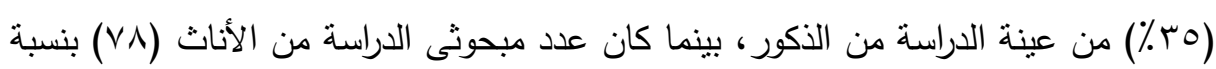

جدول(ץ): توزيع المبحوثين طبقا للحالة الاجتماعية

\begin{tabular}{|c|c|c|}
\hline النسبة" & التكرار & \\
\hline$T_{\cdot, \cdot}$ & $T \xi$ & آعزب / آنسة \\
\hline $79, Y$ & NT & متزوج / متزوجة \\
\hline$\Gamma, \Gamma$ & $\varepsilon$ & مطلق \\
\hline$V, 0$ & 9 & آرمل / آرملة \\
\hline $1 \cdots \cdot \cdot$ & Tr. & المجموع \\
\hline
\end{tabular}


من الجدول رقم (ץ) الخاص بالحالة الإجتماعية للمبحوثين بالدراسة يتضح أن عدد

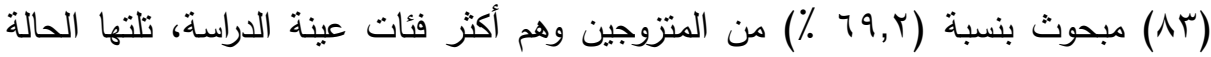

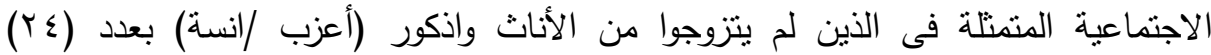

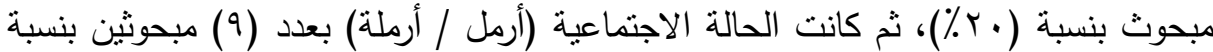

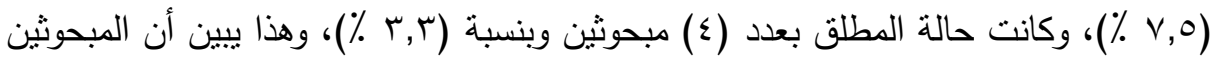
من الأرامل والمطلقين نسبتهم نقرييًا (· (1 \%) من إجمالى عينة الدراسة.

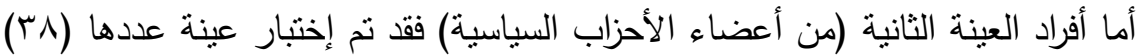

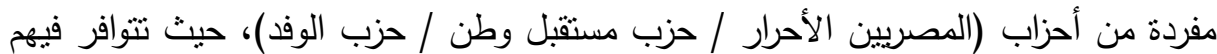

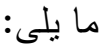

أن يكونوا من الأحزاب الأكثر تمثيلًا بمجلس النواب، تنوع النوع (ذكر / أنثى)، أن يكون

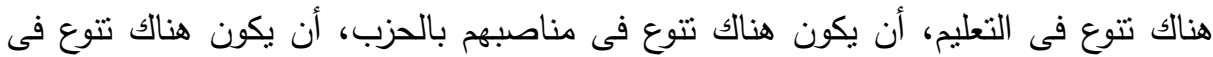

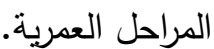

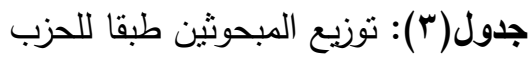

\begin{tabular}{|c|c|c|}
\hline النسبة & التكرار & \\
\hline$\varepsilon Y, 1$ & 17 & المصريين الأحرار \\
\hline$r q, \Lambda$ & $1 \varepsilon$ & مستقبقل وطن \\
\hline$r, 1$ & $\hat{\Lambda}$ & 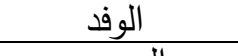 \\
\hline $1 \cdots \cdot 6$ & $r \Lambda$ & المجموع \\
\hline
\end{tabular}

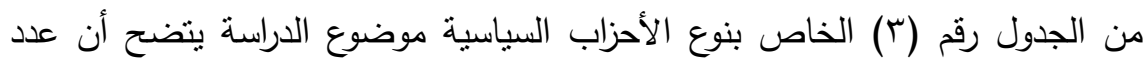

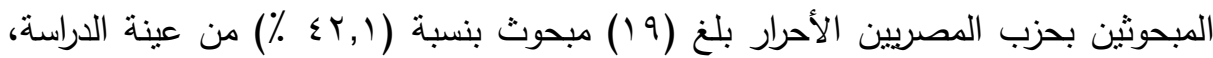

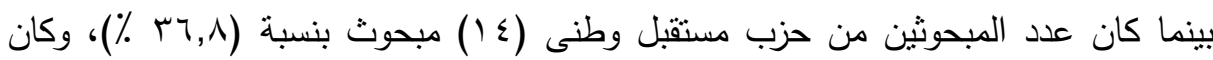

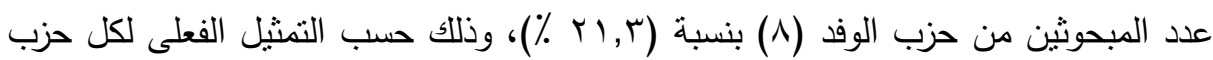

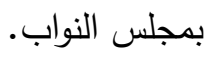
جدول(؛ ): توزيع المبحوثين طبقا للنوع

\begin{tabular}{|c|c|c|}
\hline الننببة. & التكرار & \\
\hline$\overline{V T, V}$ & $r \Lambda$ & ذكر \\
\hline$Y \bar{r}, r$ & 1. & أنثي \\
\hline $1, \ldots$ & $r \lambda$ & الهجموع \\
\hline
\end{tabular}

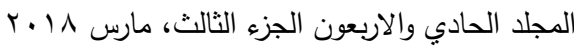


من الجدول رقم (ع) الخاص بنوع مبحوثى الدراسة من أعضاء الأحزاب الثلاثة محل

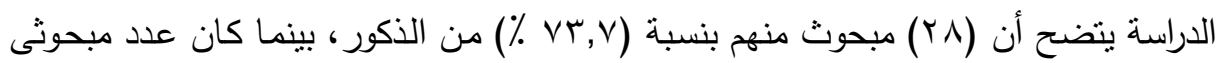

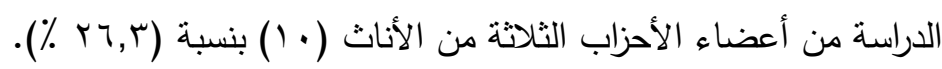

\section{أسوايه التراسلة}

استخدم الباحثون عدد (Y) إستمارة إستبيان كأداة أساسية لجمع البيانات الإحصائية

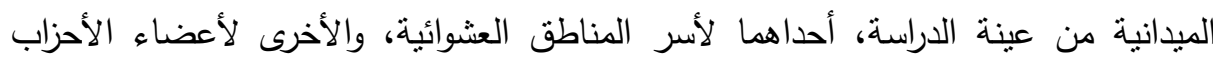

تم إعداد استمارتي الإسنبيان طبقًا للمراحل التالية: 1-تحديد البيانات المطلوبة وذللك وفقًا لأهداف الدراسة. r-تحديد محاور استمارتي الإستنيان وذللك وفقًا لأهداف الدراسة وهى كالتانئ التالي: الإستبيان الأول:- استمارة لسكان العشوائيات وبها (00) سؤالا وتتشمل الاتى : الإنى أولاً:-- بيانات أولية (الإسم- النوع- السن- الإن الحالة الإجتماعية- الحالة التعليمية- المهنة ....).

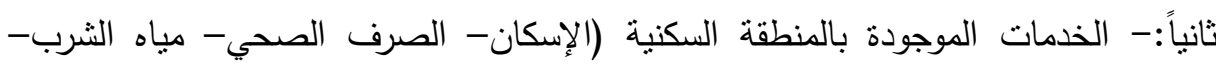

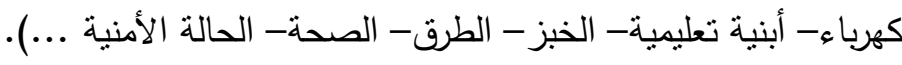

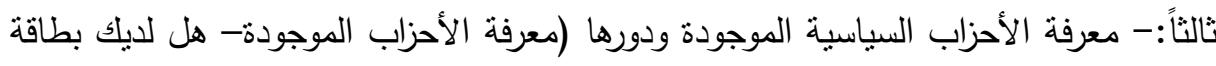

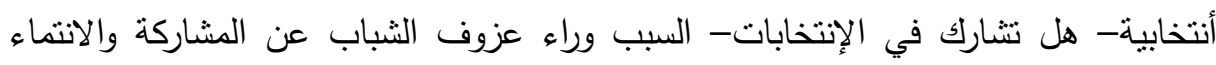

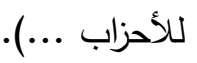
الإستبيان الثاني:- إستمارة أعضاء الحزب وبها (^ء) سؤالا وتشمل : أولاً:- بيانات أساسية عن الحزب (إسم الحزب- عنوان الحزب- ناريخ الإثهار - عدد أعضاء

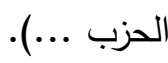
ثنانياً:- بيانات عضو الحزب التي تمت مقابلته (الإسم- النوع- السن- الحالة الإجتماعيةالحالة التعليمية- الوظيفة- أهداف الحزب- دور الحزب واسهاماته في تتمية سلوك المناطق لتان العشوائية ....). 
ثالثاً:- إسهامات الحزب فى نتمية سلوك المشاركة الثعبية لسكان المناطق العشوائية فى

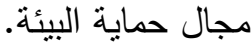

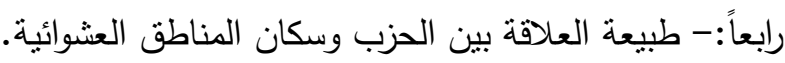
خامساً:- دور الحزب فى تتمية سلوك المشاركة الثعبية لدى سكان المناطق العشوائية. سادساً:- مشكلات الحزب. سابعاً:- مقترحات تتشيط ورفع كفاءة الحزب. سمابك. ب-الصياغة المبدئية لإستمارتي الاستبيان. ع - عرض إستمارتي الاستبيان على الخبراء المحكمين (لتحكيمهما). 0- عرض إستمارتي الاسنبيان على الدكاترة المشرفين لإبداء أرائهم وملاحظتهم. צ-عمل أختبار (مبدئي) لاستمارتي الاستنيان. V- الصياغة النهائية لإستمارتي الإستبيان بعد تعديلها بناء على ملاحظات الخبراء والمشرفين.

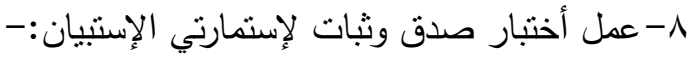
تم عمل التحليلات الإحصائية لبيانات أداة الدراسة لإستخراج النتائج الإحصائية وذلك عن

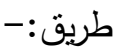

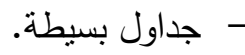

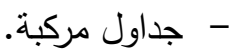

- تفريغ الأسئلة المفتوحة وتجميعها في فئات مع عمل نسبة مئوية لكل بند.

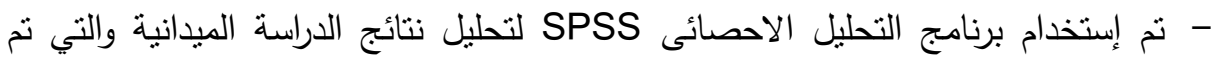

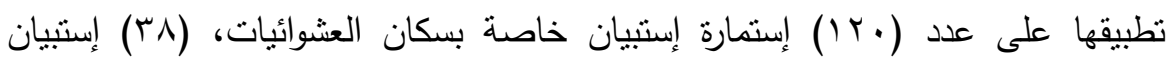

$$
\text { خاص بالأحزاب السياسية. }
$$

- الثبات ويعنى مدى اتساق المقياس مع نفسه في قياس أى بعد بنفسه، أى مدى إستقرار الدرجات التي يحصل عليها نفس الأفراد لو أعيد إجراء الإختبار .

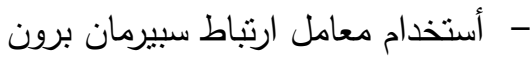
$\frac{\Omega}{\jmath+1}=$; 
- الصدق الذاتي: ويتم التعرف علية عند معامل ثبات المقياس وذلك لما بين صدق المقياس وثباته صلة وثثية حيث يحسب الصدق الذاتى بحساب الجزر التربيعى لمعامل الثبات

$$
\text { 9- النطبيق النهائي (المبداني) لإستمارتي الإسنبيان. }
$$

\section{نتمأيج التورامة}

أهم نتائج الاراسة الميدانية: يتتاول الباحث عرض النتائج التي نم الحصول عليها من الدراسة، وذللك من خلال عرض نتائج الدراسة الميدانية لسكان المناطق العشوائية وهى تتضمن

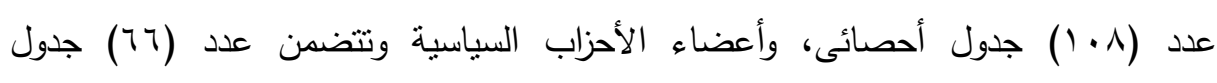

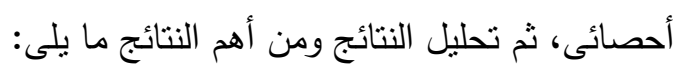

\begin{tabular}{|c|c|c|}
\hline النسبة & التكرار & \\
\hline$\varepsilon 0,$. & $0 \leqslant$ & نعح \\
\hline $00,$. & 77 & $\gamma$ \\
\hline $1 \ldots$ & $\pi$. & المجموع \\
\hline
\end{tabular}
جدول(ه): معرفة الأحزاب السياسة الموجودة على الأنى الساحة السياسية

عن معرفة الأهالى للأحزاب السياسية الموجودة على الساحة السياسية، جاءت استجابات

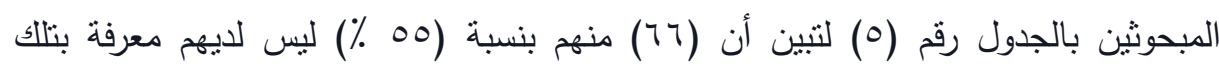

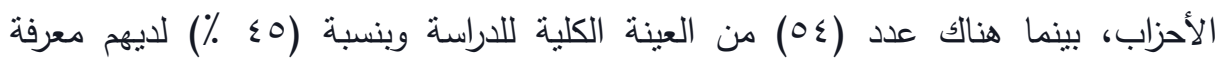

بالأحزاب السياسية الموجودة على الساحة السياسية.

\begin{tabular}{|c|c|c|}
\hline النسبة & التكرار & \\
\hline$\overline{11, V}$ & Tร & المشكلات الخاصة بالإسكان \\
\hline $1 \cdot, \cdot$ & ir & المشكلات الخاصة بالانديةًة الثبابية \\
\hline $1 \wedge, \Gamma$ & TY & المشكلات الخاصة بالّصحة \\
\hline $1 \leqslant, Y$ & IV & المشكلات الخاصة بالتعليج \\
\hline $1 \mathrm{~V}, 0$ & T) & المشكلات الخاصة بـالطرق \\
\hline $19, Y$ & TL & المشكلات الخاصة بالتموين \\
\hline $\mathrm{VI,V}$ & AT & الاححزاب لا تهت باى مشكلات خاصةٌ بالمنطقة \\
\hline- & TY. & عدد المستجبين \\
\hline
\end{tabular}
جدول(7): أهم المشكلات التي تهتم بها الأحزاب السباسية التي بعانى منها سكان المناطق العشوائية 
يوضح الجدول رقم (V) - وفيه اختبار أكثر من بديل - أهم المشكلات التي تهثم بها الأحزاب السياسية التي يعانى منها سكان المناطق العشوائية، وقد نبين أن الأحزاب لا تهنم

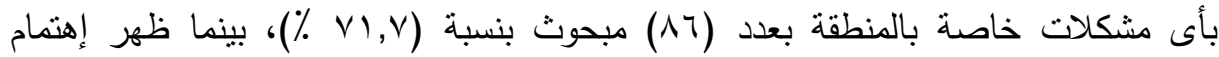

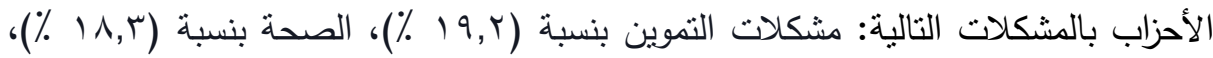
الطرق بنسبة (V,0 1 \%)، وهناك مشكلات أخر ولكن كانت أخر المشكلات الأندية الثبابية

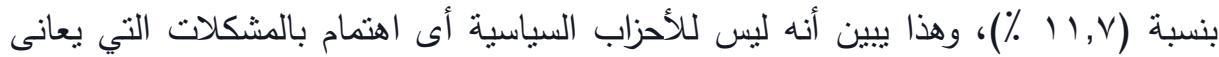
منها سكان المناطق العشوائية. جدول(V): الدور التي تقوم به الأحزاب السياسية لحل هذه المشكلات التي يعانى منها سكان المناطق العشوائية

\begin{tabular}{|c|c|c|}
\hline 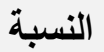 & 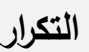 & \\
\hline 0, & 7 & وضع خطط تتفيذية للقضاء على التسرب الدراسي \\
\hline $9, Y$ & 11 & القيام بتتفيذ برامج محوالأمية \\
\hline $9, Y$ & 11 & القيام بالتوعية بمخاطر الزيادة السكانية \\
\hline $11, \mathrm{~V}$ & $1 \leq$ & وضع برامج تتفيذية للقضاء على ظاهرة أطفال الشوارع \\
\hline $\mathrm{V}, \mathrm{O}$ & 9 & التوعية بمخاطر الإدمان والانحراف \\
\hline$T \leqslant, Y$ & rq & الاهتمام بالخدمات والمرافق الصحية \\
\hline$V \cdot, \Lambda$ & 10 & ليس لها دور \\
\hline- & Tr. & عدد المستجبين \\
\hline
\end{tabular}
*اختبار أكثز من بديل يوضح الجدول رقم (^) - وفيه اختبار أكثر من بديل - الدور الذى تقوم به الأحزاب

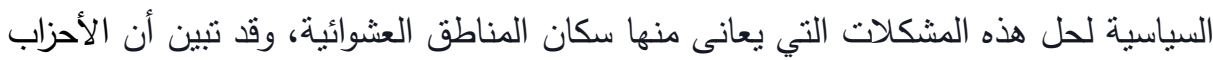

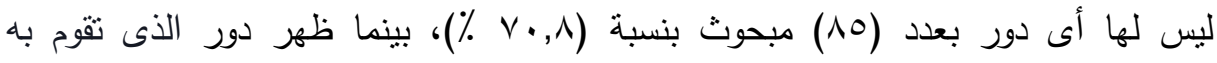

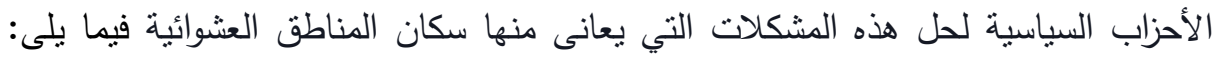

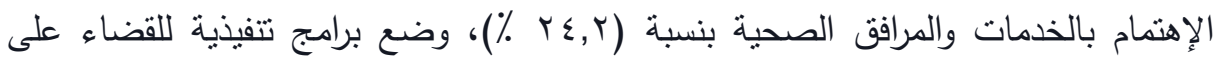

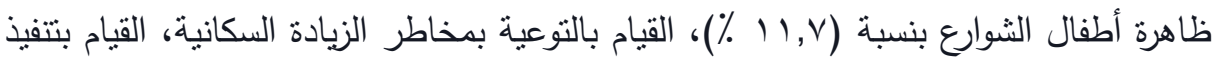

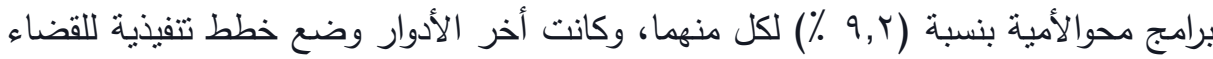
على التسرب الدراسي بنسبة (ه \%)، وهذا يبين أنه ليس للأحزاب السياسية أى أدوار فى حلى حل المشكلات التي يعانى منها سكان المناطق العشوائية.

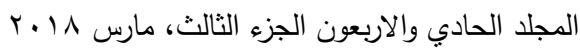


مجلة العلوم البيئية

معهد الدراسات والبحوث البيئية - جامعة عين شمس لئه

جدول(^): الرضا عن دور الأحزاب السباسية فى تحقيق وحل المشكلات البيئية

\begin{tabular}{|c|c|c|}
\hline النسببة & التكرار & \\
\hline $\bar{V}, 0$ & $\overline{9}$ & نعم راضي \\
\hline 94,0 & 111 & غير راضى \\
\hline$\cdots$ & $T r$. & المجموع \\
\hline
\end{tabular}

نتاول الجدول رقم (^) الرضا عن دور الأحزاب السياسية فى تحقيق وحل المشكلات

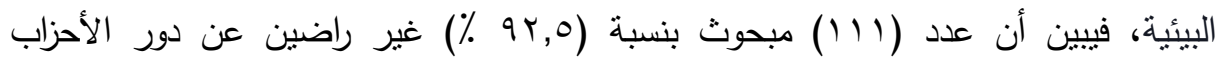

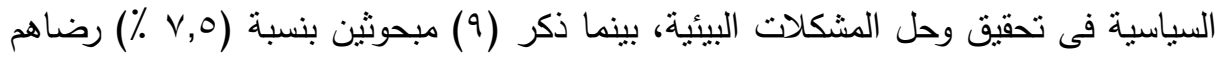
عن دور الأحزاب السياسية فى تحقيق وحل المشكلات البيئية، وهذا يبين عدم رضى عينة الدراسة عن دور الأحزاب السياسية فى تحقيق وحل المشكلات البيئية.

يعرض الباحث فيما يلى إحصائية مبسطة عن الأحزاب محل الدراسة الحالية، وذلك على دلى

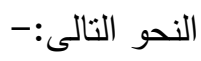

جدول(9): دور الأحزاب السياسية المصرية فى تتمية سلوك المشاركة الثعبية لمواجهة بعض الثض المشكلات البيئية لدى سكان المناطق العشوائية فى مجال حماية البيئة من وجهة لئه

\begin{tabular}{|c|c|c|}
\hline النسبة & التكرار & \\
\hline$Y 1,1$ & 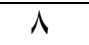 & لها دور \\
\hline$T \pi, Y$ & $T \varepsilon$ & لها دور إلى حد ما \\
\hline 10,1 & 7 & لبس لها دور \\
\hline $1 \cdots 6$ & rᄉ & المجموع \\
\hline
\end{tabular}

يتتاول الجدول رقم (9) دور الأحزاب السياسية المصرية فى نتمية سلوك المشاركة الشعبية لمواجهة بعض المشكلات البيئية لدى سكان المناطق العشوائية فى مجال حماية البيئة

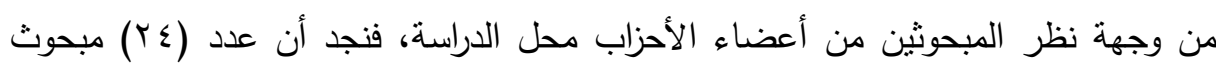

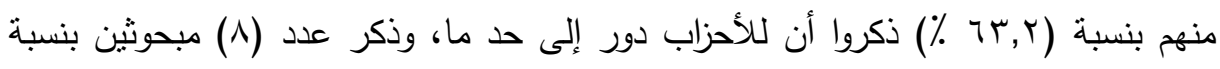

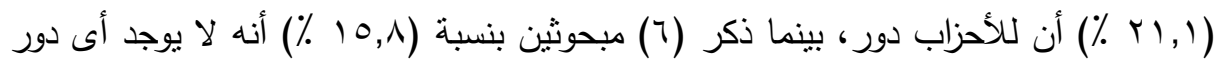

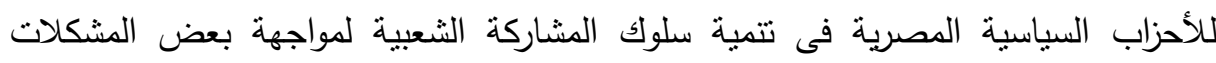

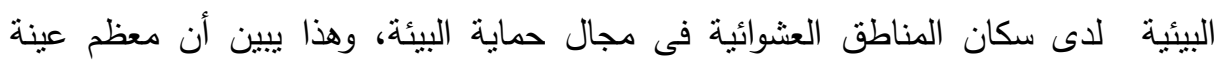

$$
\text { المجلد الحادي والاربعون الجزء الثالث، مارس ^| • ب }
$$


الدراسة من أعضاء الأحزاب برون أن للأحزاب دور فى نتمية سلوك المشاركة الثعبية لمواجهة بعض المشكلات البيئية لاى سكان المناطق العشوائية. جدول( • 1): وجود حوار بين الحزب وسكان المناطق العشوائية

\begin{tabular}{|c|c|c|}
\hline النسبة & التكرار & \\
\hline$\varepsilon Y, 1$ & 17 & دائم \\
\hline $0 Y, 7$ & r. & نادر \\
\hline $0, r$ & $\bar{r}$ & غبر موجود \\
\hline $1 \ldots$. & rᄉ & المجموع \\
\hline
\end{tabular}

تتاول الجدول رقم (• (1) وجود حوار بين الحزب وسكان المناطق العشوائية، فنجد أن عدد (·r) مبحوث منهم بنسبة (T,Yor \%) ذكروا أن حوار بين الحزب وسكان المناطق

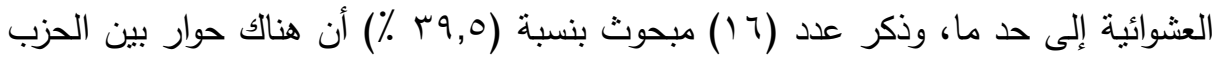

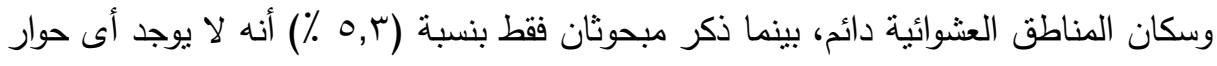

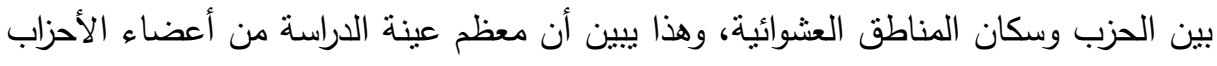
يرون أن هناك حوار بين الحزب وسكان الدناطق العشوائية. أهم النتائج التى توصلت لها الدراسة: النتيجة الرئيسية: كانت أهم نتيجة ظهرت من نتائج الدراسة الميدانية هى إختلاف آراء المبحوثين من سكان المناطق العشوائية مع آراء أعضاء المبحوثين من الأحزاب محل الدراسة في كل الأسئلة المتشابهة. ومن أهم النتائج الخاصة بسكان المناطقة العنابة العثوائية: 1- هناك تفاوت كبير جدًا بين مبحوثى الدراسة فيما يخص قناعتهم بكفاية العائد من دخلهم. r- هناك تفاوت كبير جدًا بين مبحوثى الدراسة فيما يخص وجود وعدم وجود حقوق تأمينية وصحية بالعمل. r- قامت الدولة بتوفير شبكة عامة للصرف الصحى على الرغم من أن تلك المناطق عشوائية. ع- قامت الدولة بتوفير شبكة عامة للمباه وهى صالحة للشرب على الرغم من أن تلك المناطق عشوائية.

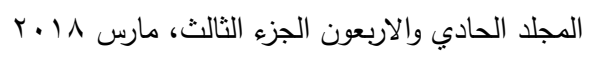


ه- غالبية عينة الدراسة بالمناطق الثلاثة راضية عن توفير شبكة عامة للمياه وهى صالحة للشرب كما أنها راضية عن جودتها على الرغم من أن تلك المناطق عشوائية. 7- أكد جميع المبحوثين على وجود شبكة كهرباء. V- غالبية المبحوثين من عينة الدراسة بالمناطق الثلاثة الذين ذكروا وجود مستودع بوثاجاز بالمنطقة ذكروا أن هناك تعاون بين مسئولى مستودع البوتاجاز مع الأهالى بتلك المناطق عشوائية.

ᄉ- قامت الدولة بتوفير هيئات شبابية (مراكز شباب) لسكان المناطق العشوائية لممارسة الأنشطة المختلفة سواء رياضية أوثقافية.

9- ذكر معظم عينة الدراسة عدم توافر ملاعب تابعة للثباب والرياضة لسكان المناطق النقاه العشوائية لممارسة الأنشطة الرياضية.

• 1 يرى ما يقرب من خمسى العينة أن هناك أملاك دولة يمكن أستئجارها بالمنطقة لسكان المناطق العشوائية لممارسة الأنشطة الرياضية عليها.

1ا - قامت الدولة بتوفير المدارس الإبتدائية والإعدادية لسكان المناطق العشيهائية العية لتسهيل العملية التعليمية لأبناء سكان تلك المناطق العشوائية. r r ا غالبية عينة الدراسة ذكروا أنه مطلوب إنشاء مدارس بالمنطقة. rا - أبناء سكان تلاك المناطق العشوائية يتوافر لكل منهم ما لا يقل عن ثلاثة أرغفة يوميًا. ع ا- غالبية عينة الدراسة ذكروا أن عدد الأفران البلدى بالمنطقة كاف، وكذلك عدد الأفران الطباقى بالمنطقة كاف.

10- غالبية عينة الدراسة راضين عن جودة رغيف العيش بالمنطقة، كما أنهم راضين عن مسنوى أداء الأفران من حيث الجودة، والأمانة، والتعامل مع الجمهور بالمنطقة رغينة ألع 17 - معظم العينة تعانى من الطرق بالمناطق العشوائية.

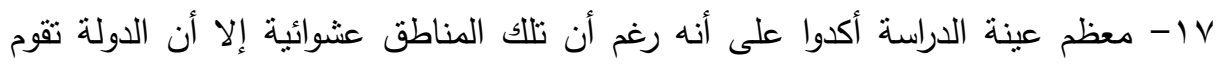

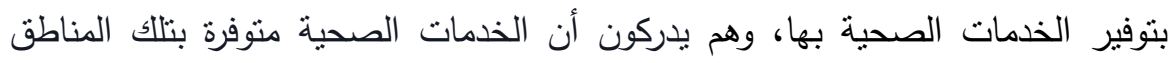
العشوائية. 
1 - - معظم أفراد العينة قد ذكروا أن أبرز الخدمات الصحية المفتقدة بتلك المناطق العشوائية

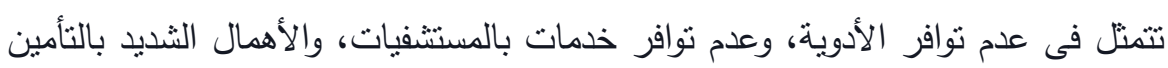

9 1 - معظم أفراد العينة اقترحوا تحسين مستوى أداء الخدمة وتوفر العلاج لكل الأفراد.

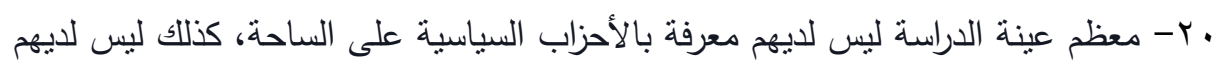

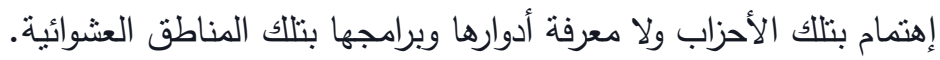

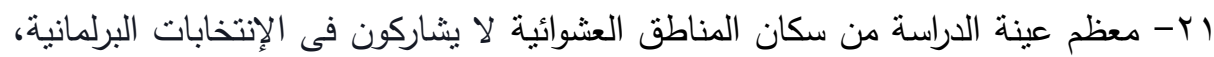

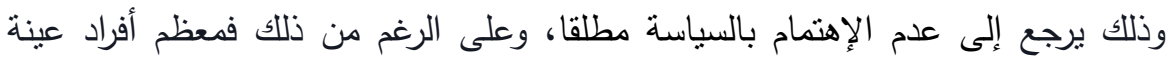
الدراسة راضين عن نزاهة الإنتخابات.

r r- عينة الدراسة تميل قليلًا جدا" نحوالثقة فى الحكومة والأحزاب السياسية. r ب - الثباب غير حريصين على المشاركة فى الأحزاب السياسية.

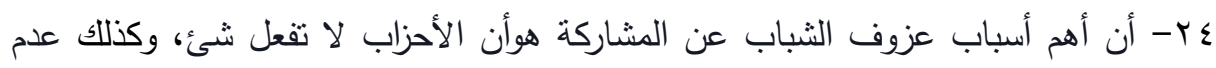
وجود حزب يعبر عن أفكارهم، بالإضافة إلى عدم إهتمام الثباب بالسياسة. 0ץ- الأسرة لا تقوم بدورها فى مساعدة الثباب وتشجعيهم على المشاركة فى السياسة.

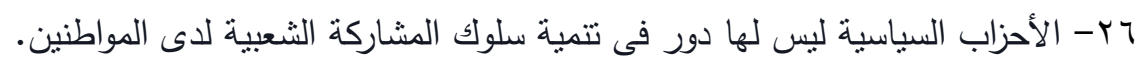

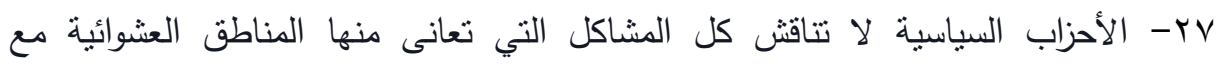

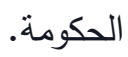

^ץ - الأحزاب السياسية لا تتصدى لأى مشكلة طارئة فى المناطق العشوائية. وץ- الأحزاب السياسية لا نطالب الحكومة بإحتياجات سكان المناطق العشوائية.

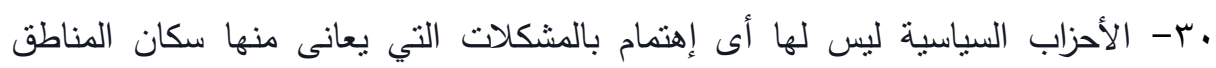
العشوائية.

اب- الأحزاب السياسية لبس لها أى أدوار فى حل المشكلات التي يعانى منها سكان المناطق العشوائية. r ب- عدم رضى عينة الدراسة عن دور الأحزاب السياسية فى تحقيق وحل المشكلات البيئية.

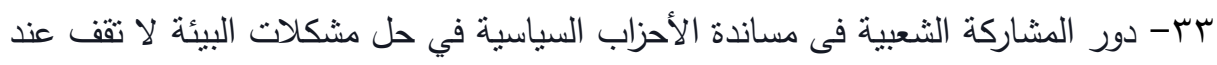

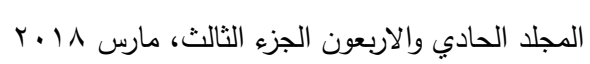


سن معين، ولكن عند الأكبر تكون أوضح، وكذلك عدم وضوح دور المشاركة الثعبية فى

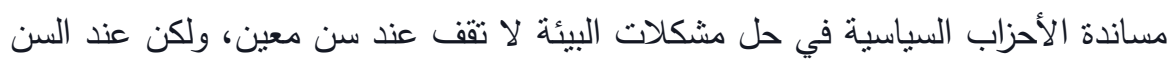
الأصغر تكون أوضح.

ع ז- جميع المراحل السنية من سكان المنطقة بأملون فى مجالات وأنشطة محددة تقوم بها الأحزاب السياسية فى حماية البيئة بمنطقة السكن. هr- عينة الدراسة ذكرت مقترحات عديدة لتفعيل دور الأحزاب السياسية فى نتمية سلوك بله

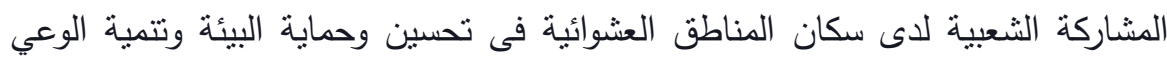

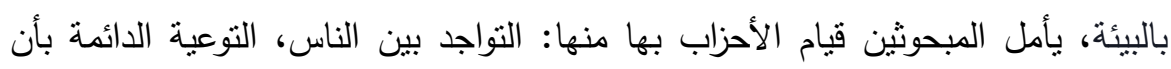

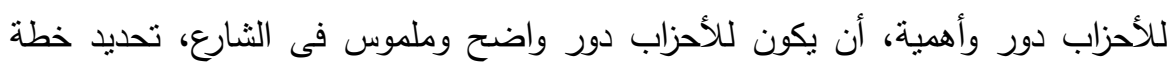
عمل لها بالمنطقة تسعى لتحقيقها بناء على الواقع.

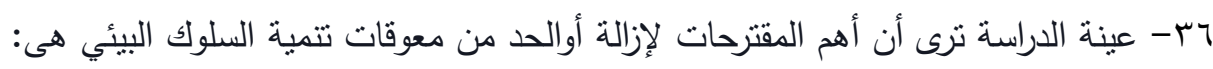
إنتثـار عادات وقيم سلوكيات تتفق وحسن استغلال، دعم الإمكانيات (تمويل - عناصر

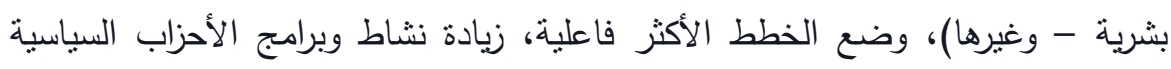

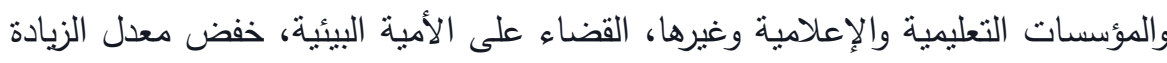

\section{ومن أهم النتائج الخاصة بأعضاء الأحزاب السياسية:}

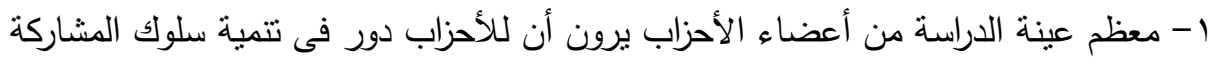

$$
\text { الثعبية لمواجهة بعض المشكلات البيئية لدى سكان المناطق العشوائية. }
$$

r- معظم عينة الدراسة من أعضاء الأحزاب يرون أن للأحزاب السياسية دور فى القيام بتوعية سكان المناطق العشوائية بتتمية سلوك المشاركة لحل مشكلاتهم، وهذه النتيجة تختلف تماماً مع نتيجة المبحوثين من سكان المناطق العشوائية الذين ذكروا غياب هذا

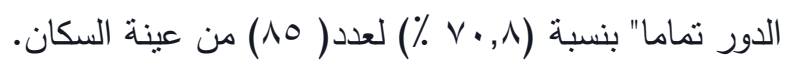

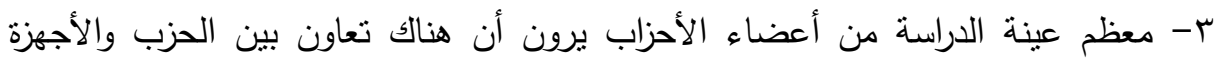

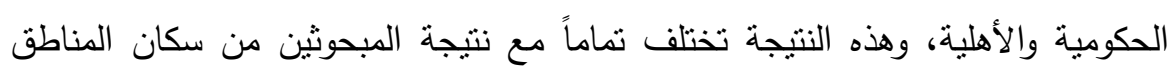

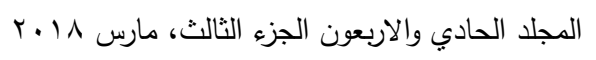


العشوائية الذين ذكروا عدم مناقثة الأحزاب السياسية المشاكل التي تعانى منها المناطق

$$
\text { العشوائية مع الحكومة. }
$$

ـ - معظم عينة الدراسة من أعضاء الأحزاب يرون أن الحزب يقدم خدمات ضرورية لسكان

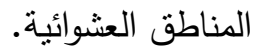

ه- جميع أفراد عينة الدراسة من أعضاء الأحزاب يرون أن الحزب يقدم ببرامج للتوعية

$$
\text { السياسية والثقافية والبيئية. }
$$

צ- معظم عينة الدراسة من أعضاء الأحزاب يرون أن هناك تتمية للسلوك فى الحزب لتحقيق

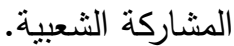

V- معظم عينة الدراسة من أعضاء الأحزاب يرون أن العلاقة بين الحزب وسكان المناطق

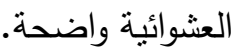

^- معظم عينة الدراسة من أعضاء الأحزاب برون أن هناك حوار بين الحزب وسكان

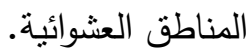
9- معظم عينة الدراسة من أعضاء الأحزاب يرون أن هناك إقتاع من السكان بأهية

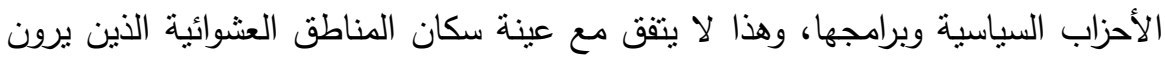

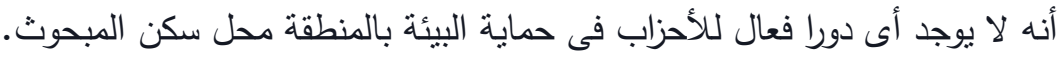

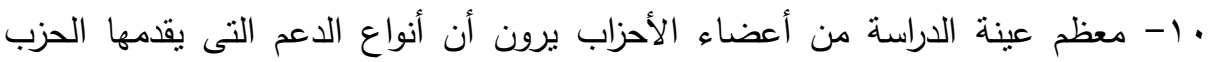

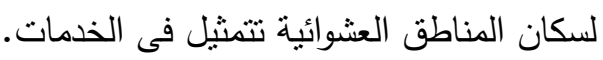
11 - معظم عينة الدراسة من أعضاء الأحزاب برون أن ذلك يساعد في دعم الحزب للقيات للقيام ببرامج لحماية البيئة. r ا أكثر من نصف عينة الدراسة من أعضاء الأحزاب يرون أن سكان المناطق العشوائية

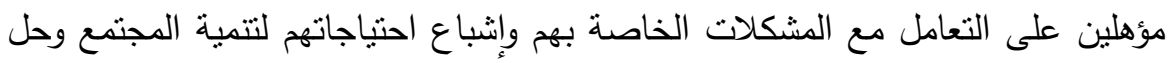
مشاكلهم البيئية. rا - معظم عينة الدراسة من أعضاء الأحزاب يرون أن الأحزاب السياسية تتيح الفرص لتئة

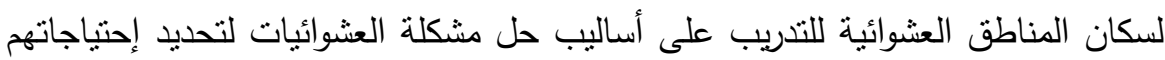
الفعلية واكتساب الخبرة لمواجهة أى مشكلات وعقبات بيئية نواجههم.

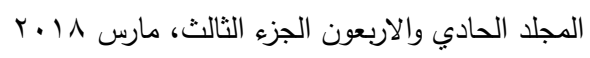


ـ ا- جميع أعضاء الأحزاب المشاركين بالدراسة ذكروا وجود مشاركة بين الأجهزة المحلية

$$
\text { (المجالس المحلية والثعبية) والأحزاب. }
$$

10 - أغلب المبحوثين من أعضاء الأحزاب بالدراسة ذكروا أن هنالك تدخل من الحكومة فى وابل إدارة وبرامج الأحزاب.

71 - أغلب المبحوثين من أعضاء الأحزاب بالدراسة ذكروا أن العلاقة بين الحكومة الأحزاب واضحة، وأن ذلك من عوامل نجاح الأحزاب.

V V أغلب المبحوثين من أعضاء الأحزاب بالدراسة كان الفراب. الفرق بين موافقتهم، وموافقتهم إلى منى

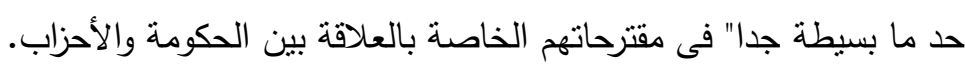

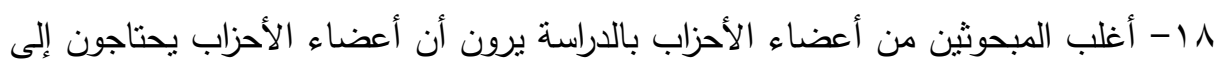
تدريب.

9 ا- أغلب المبحوثين من أعضاء الأحزاب بالدراسة برون أن الأحزاب فى حاجة إلى

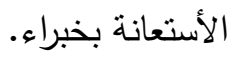

\section{تركياهي التراسة}

\section{ومن أهم النتائج الخاصة بسكان المناطق العشوائية:}

1- ضرورة العمل على توفير ملاعب تابعة للثباب والرياضة لسكان المناطق العشوائية

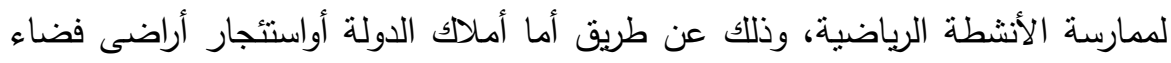

بالمناطق العشوائية لممارسة سكانها الأنشطة الرياضية عليها.

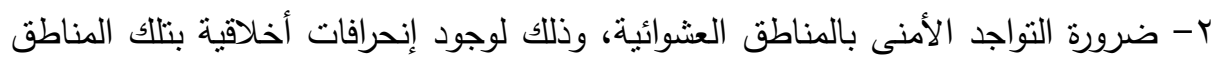
العشوائية، وإنتشار الجرائم السلوكية بها. r- ضرورة أن يكون للأحزاب السياسية دور ومكانة على الساحة وبرامج، حتى يعرف الناس بهاس تلك الأحزاب وأدوارها ومكانها. ع- ضرورة أن يكون للأحزاب السياسية والحكومة دور مع سكان المناطق العشوائية حتى يشاركون فى الإنتخابات البرلمانية. 
ه- ضرورة تتجيع الثباب على المشاركة فى الأحزاب السياسية، والعمليات الانتخابية. צ- ضرورة العمل على تلافى أسباب عزوف الثباب عن المشاركة السياسية وعدم إهتمامهم

V- ضرورة قيام الأسرة بدورها فى مساعدة الثباب وتشجعيهخ على المشاركة فى السياسة.

^- ضرورة قيام الأحزاب السياسية بدور فى نتمية سلوك الششاركة الثعبية لدى المواطنين.

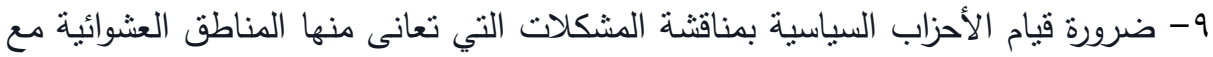

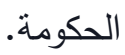

• 1 ضرورة أن يكون للأحزاب السياسية دور فى مطالبة الحكومة بإحتباجات سكان المناطق

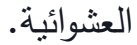

1) ضرورة أن يكون للأحزاب السياسية دور فى إقناع سكان المناطق العشوائية بجميع المراحل العمرية بدورهم، عن طريق العمل الجاد والبرامج الجاذبة والهادفة. r ا ضرورة أن تتوافق المبادئ والثعارات وسياسات وبرامج الأحزاب السياسية وبين الإرادة الثعبية للمواطنين.

rا - ضرورة أن يكون هناك دور للأحزاب السياسية دوراً فعالاً فى حماية البيئة بالمناطق

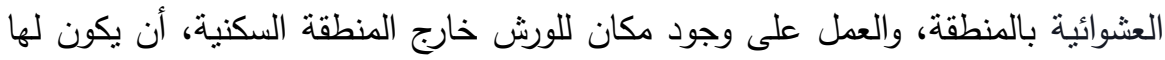

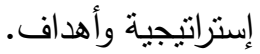

\section{ومن أهم النتائج الخاصة بأعضاء الأحزاب السياسية:}

1- ضرورة قيام الأحزاب السياسية بدور فى القيام بتوعية سكان المناطق العشوائية بتتمية

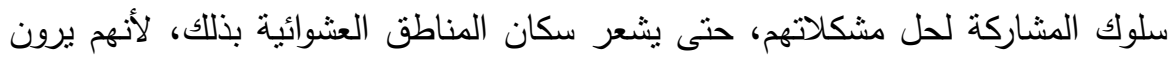

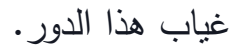

r- ضرورة قيام الأحزاب السياسية بدور فعال فى مناقثة المثاكل التي تعانى منها المناطق

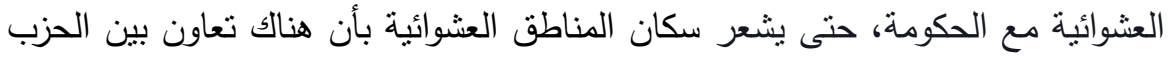


r- ضرورة تشجيع الحكومة للأحزاب على أن يكون هناك حوار بين الحزب وسكان المناطق

$$
\text { العشوائية. }
$$

ع - ضرورة أن يكون هناك دور فعال للأحزاب السياسية فى حماية البيئة، بحيث يشعر به

$$
\text { سكان تلأك المناطق. }
$$

ه- ضرورة تتوع أنواع الدعم التى يقدمها الحزب لسكان المناطق العشوائية ليشعر بها سكان

$$
\text { تلألك المناطق. }
$$

צ- ضرورة تشجيع الأحزاب السياسية على إناحة الفرص لسكان المناطق العشوائية للتدريب

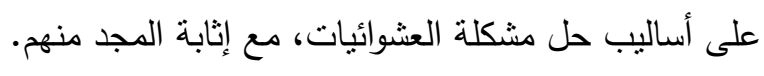

V- ضرورة تنجيع وتقوية الششاركة بين الأجهزة المحلية (المجالس المحلية والثعبية)

$$
\text { والأحزاب. }
$$

^- ضرورة العمل على إيجاد صورة للعلاقة بين الحكومة والأحزاب، مع عدم تدخل الحكومة

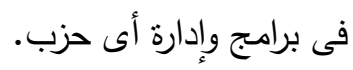

$$
\text { 9- ضرورة قيام الأحزاب السياسية بتدريب أعضائها. }
$$

$$
\text { • 1- ضرورة استعانة الأحزاب بخبراء فى مختلف المجالات. }
$$

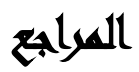

السيد محمد الحسيني( § 99 (): دراسة إجتماعية للمدينة، القاهرة، مؤسسة نبيل للطباعة.

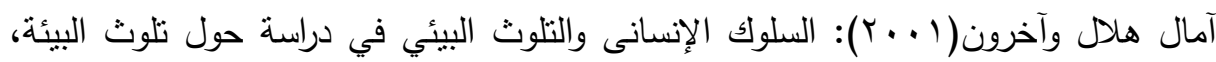

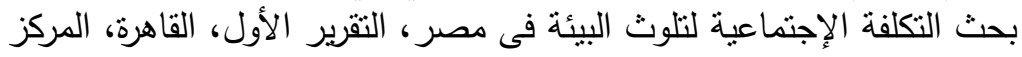

القومى للبحوث الإجتماعية والجنائية.

أميرة كمال محمد عنب(991 (191): دور المشاركة الثعبية في تطوير المناطق العشوائية، دراسة

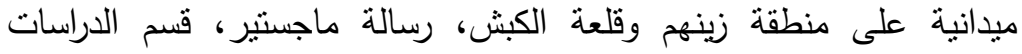
الإنسانية، معهد البحوث والدراسات البيئية.

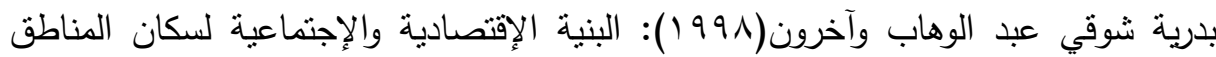

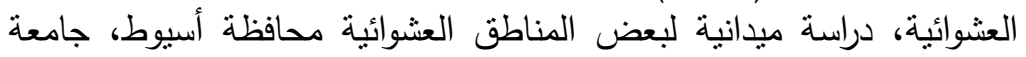
أسيوط، مركز دراسات المستقبل.

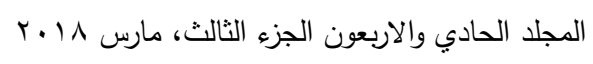


بطرس غالى، محمود خيري(991 (1)): مدخل في علم السياسة، ط • (، القاهرة، مكتبة الأنجلو

$$
\text { المصرية. }
$$

جمال شحاتة وآخرون(ع 99 ()): الإنسان والبيئة في إطار مهنة الخدة الإجتماعية، القاهرة،

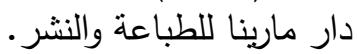

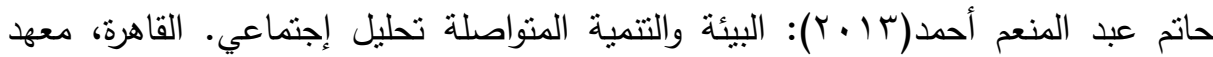
الدراسات والبحوث البيئية، جامعة عين شمس.

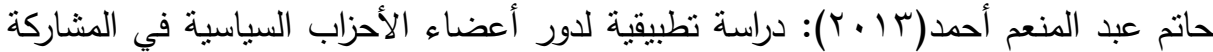

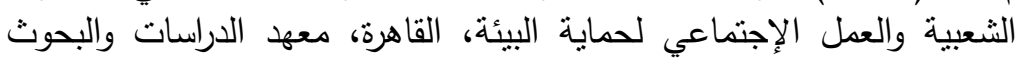
البيئية، جامعة عين شمس.

رمزي الثاعر(به91 ()): النظرية العامة للقانون الدستوري، الطبعة الثالثة، القاهرة، دار النهضة

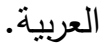

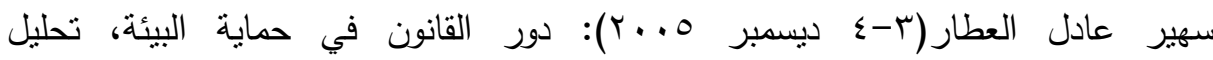
سيسيولوجى، المؤتمر السنوي العانر ، إدارة الأزمات والكوارث البيائية في ظل فلئية

$$
\text { المتغيرات والمستجدات العالمية المعاصرة. }
$$

سليمان الطماوى(997): السلطات الثلاث في الدساتير العربية المعاصرة وفى الفكر

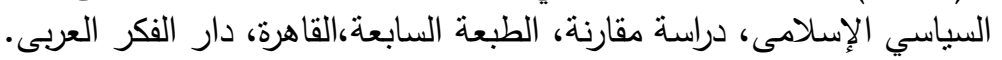

عادل السكرى(999): آفاق تربوية متجددة (نظرية المعرفة)، طا، القاهرة، الدار المصرية اللبنانية.

عبد الهادي الجوهري(ـ19 1): المشاركة الثعبية في سلسلة تقارير مجلس الثورى، جمهورية

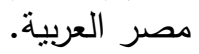

عبد الخالق عفيفي(1997) (19): تتظيم المجتمع، النشأة والتطور ، القاهرة، مكتبة القصر العيني.

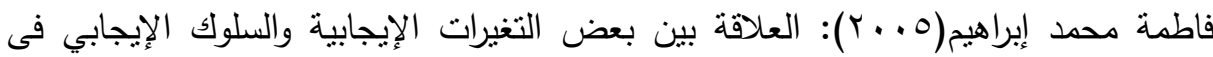

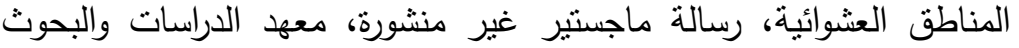
البيئية، جامعة عين شمس.

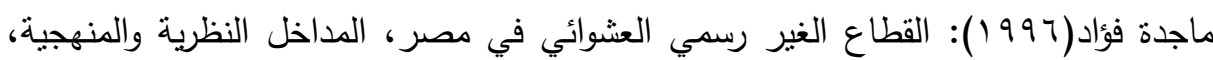
التقريرالأول، القاهرة، المركز القومي للبحوث الإجتماعية والجنائية.

محمد عاطف غيث(9191): المشاكل الإجتماعية والسلوك الإنحرافي، الأسكندرية، دار

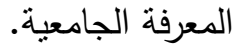

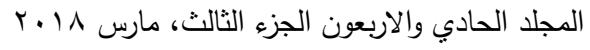




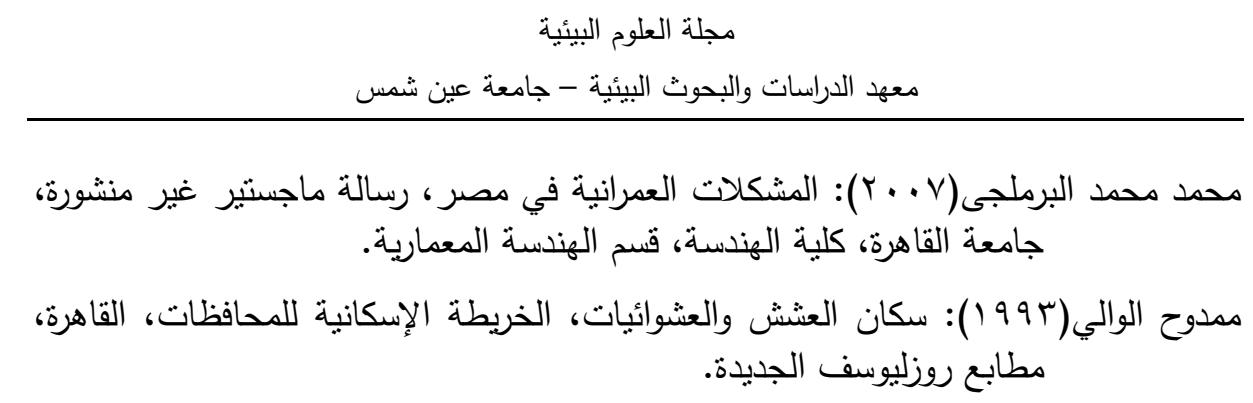

Alan Twelvetress , Community Work Practice Social Work, 1991.

Peter. P. E. Kett, Social Exchange Theory, London, Heneman, 1974.

Ed., Series Editor, Jocanpling, M. Macmillan, BAS.W., 1991.

Erich Fromm, Fear of Freedom (London,routledge and Kegan Paul, 1960.

Erich Fromm, The Society, (London,routledge and Kegan Paul,1968.

\title{
THE ROLE OF EGYPTIAN POLITICAL PARTIES IN DEVELOPING POPULAR PARTNERSHIP BEHAVIOR FOR MEETING ENVIRONMENTAL
} PROBLEMS AMONG SLUM AREAS INHABITANTS

Hefny, K. M. ${ }^{(1)}$; A. M. Al Ateeq ${ }^{(2)}$ and Sadek, M.G. ${ }^{(3)}$

1) Institute of Motherhood and Childhood, Ain Shams University

2) Institute of Environmental Studies and Research, Ain Shams University 3) National Center for Social and Criminal Research

\begin{abstract}
This study deals with the role of the Egyptian political parties in developing the behavior of popular participation to confront some environmental problems in the population of the informal settlements. The study studies the role of political parties in facing environmental issues and the need of decision makers for such study. How to develop the behavior of popular participation to address the environmental 328

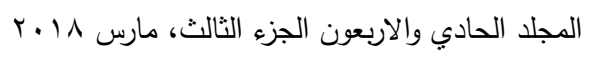


قدري محمود حفني وآخرون

problems experienced by the inhabitants of the informal settlements and to identify the programs and policies set by the parties to solve these environmental problems and the availability of political parties opportunities for the population of those areas.

The questionnaire was used to identify the actual needs and to acquire experience and knowledge to face these problems. In order to achieve this, the study uses the social survey method by means of the sample in the field study. The data were collected through questionnaire and personal interviews. (38) members of the political parties (120) from inhabitants of the informal settlements.

The results shows that political parties do not play an active role in the development of the popular participation behavior of the population of the slums. Therefore, the study recommends that there be an active and positive role for political parties with these areas and work to develop their behavior and participation in solving the problems they suffer so that the residents of the informal settlements that there is dialogue between them and there is cooperation between the party and government agencies and that they have an active role in solving their problems. 